\title{
NU-WRF Aerosol Transport Simulation over West Africa: Effects of Biomass Burning on Smoke Aerosol Distribution
}

\author{
TAKAMICHI IGUCHI AND TOSHIHISA MATSUI \\ Earth System Science Interdisciplinary Center, University of Maryland, College Park, College Park, and NASA \\ Goddard Space Flight Center, Greenbelt, Maryland \\ ZHINING TAO AND DONGCHUL KIM \\ Universities Space Research Association, Columbia, and NASA Goddard Space Flight Center, Greenbelt, Maryland \\ CHARLES M. ICHOKU \\ NASA Goddard Space Flight Center, Greenbelt, Maryland \\ LUKE ELLISON \\ Science Systems and Applications, Inc., Lanham, and NASA Goddard Space Flight Center, Greenbelt, Maryland \\ JUN WANG \\ Department of Chemical and Biochemical Engineering, Center for Global and Regional Environmental Studies, \\ The University of Iowa, Iowa City, Iowa
}

(Manuscript received 4 October 2017, in final form 30 March 2018)

\begin{abstract}
Series of aerosol transport hindcasts for West Africa were conducted using the Weather Research and Forecasting (WRF) Model coupled to chemistry within the NASA-Unified WRF (NU-WRF) framework. The transport of biomass-burning aerosols in April and December 2009 was investigated over two types of simulation domains. One-month simulations with 9-km grid spacing for April or December 2009 covered most of North and West Africa and were evaluated by comparison with measurements of the total-column aerosol optical depth, Ångström exponent, and horizontal wind components at various pressure levels. The horizontal wind components at $700 \mathrm{hPa}$ were identified as key factors in determining the transport patterns of biomass-burning aerosols from sub-Saharan West Africa to the Sahel. The vertical accumulation of biomass-burning aerosols close to $700 \mathrm{hPa}$ was demonstrated in 1-day simulations with 1-km horizontal grid spacing. A new simple parameterization for the effects of heat release by biomass burning was designed for this resolution and tested together with the conventional parameterization based on fixed smoke injection heights. The aerosol vertical profiles were somewhat sensitive to the selection of parameterization, except for cases with the assumption of excessive heating by biomass burning. The new parameterization works reasonably well and offers flexibility to relate smoke transport to biomass-burning plume rise that can be correlated with the satellite fire radiative power measurements, which is advantageous relative to the conventional parameterization.
\end{abstract}

\section{Introduction}

The climate of West Africa is influenced by aerosols from various sources. Biomass-burning aerosols, particularly, yield significant uncertainties in deducing aerosol impacts

Corresponding author: Takamichi Iguchi, takamichi.iguchi@ nasa.gov on climate. Biomass burning in West Africa is mostly from bush fires in the savanna as well as forest and cropland fires due to prevalent agricultural practices and wood burning for fuel (e.g., Delmas et al. 1991; Ichoku et al. 2016). Biomass burning in West Africa has a clear seasonal cycle, with an annual peak around the December-January timeframe (e.g., Swap et al. 2002; Ichoku et al. 2008; Roberts et al. 2009; Reeves et al. 2010). Previous studies have explored 
many aspects of biomass burning in relation to the atmospheric composition, weather, and climate of Africa (e.g., Cautenet et al. 1999; Abel et al. 2005; Johnson et al. 2008; Milton et al. 2008; Myhre et al. 2008; Liousse et al. 2010; Tummon et al. 2010; Sakaeda et al. 2011; Gatebe et al. 2014; Shi et al. 2014; Zhang et al. 2014).

Globally, many numerical simulations have been conducted in an effort to reproduce smoke transport events at various locations and have been compared with in situ and remote sensing observations for validation. For example, a modeling study demonstrated how the forest fires in Quebec, Canada, affected the air quality near the surface in Washington, D.C., and its environs through the transport of smoke aerosols (Colarco et al. 2004). Transport of dense smoke from the Yucatan Peninsula and its vicinity to a wide area of the United States was reproduced by a regional model (Wang et al. 2006). That study proved the importance of introducing appropriate diurnal variability of smoke emission in the model. On the other hand, several studies have adapted numerical models for improved representation of wildfire smoke plumes and their injection into the different layers of the atmosphere. For example, the injection of a smoke plume into the lower stratosphere was simulated using a three-dimensional (3D) plume model, and the dependency of the injection height on the amplitudes of the sensible heat and moisture fluxes was investigated (Trentmann et al. 2006; Luderer et al. 2006). A one-dimensional (1D) cloud-resolving model was embedded in a $3 \mathrm{D}$ coarseresolution chemical transport model to explicitly parameterize the vertical transport of gases and particles released by wildfires (Freitas et al. 2007). The assumption for parameterized smoke injection heights in simulations for northern sub-Saharan Africa was evaluated in comparison with the Cloud-Aerosol Lidar with Orthogonal Polarization (CALIOP) on the Cloud-Aerosol Lidar and Infrared Pathfinder Satellite Observations (CALIPSO) satellite (Yang et al. 2013). However, the effect of biomass burning as a source of heat driving smoke transport has not been sufficiently explored in such models, particularly within the African context at mesogamma $(1-20 \mathrm{~km})$ scales, despite the fact that satellite-based data have revealed the important correlation between smoke plume height and fire radiative energy (FRE) at pixel $(1 \mathrm{~km})$ and subpixel levels (e.g., Peterson et al. 2014).

The present study conducts aerosol transport hindcast simulations over West Africa using the Weather Research and Forecasting (WRF) Model coupled to chemistry (WRF-Chem) within the NASA-Unified WRF (NU-WRF; Peters-Lidard et al. 2015) framework. First, 1-month simulations for April and December 2009 were conducted with 9-km grid spacing covering most of North and West Africa. These simulations aim at demonstrating aerosol transport during the different months over the whole of West Africa and evaluating the model hindcast capability through comparison with remote sensing measurements. Second, 1-day simulations with 1-km grid spacing were conducted for small domains with active biomass burning. These simulations focused on a new parameterization of the vertical transport of biomassburning aerosols as a function of smoke lifting and injection powered by the heat release from the fire.

This study utilizes a daily high-resolution biomassburning emission product based on the satellite measurements of FRE release rates or power (FRP) and aerosol optical depth (AOD; Ichoku and Kaufman 2005; Ichoku and Ellison 2014). These emission data are ingested into the NU-WRF model to evaluate its efficacy for use in aerosol transport hindcasts. In addition, a new parameterization scheme has been designed to introduce the impacts of latent and sensible heat fluxes released by biomass burning on the smoke injection and transport as constrained by the satellite-measured FRP. This parameterization is tested in the 1-km grid-spacing simulations.

The descriptions of the aerosol transport model, hindcast configuration, and measurement datasets are provided in section 2 . The simulation results are analyzed and discussed in section 3. A summary and our conclusions are presented in section 4 . The new parameterization approach is described in the appendix.

\section{Methodology}

\section{a. The NU-WRF}

NU-WRF is a modeling system integrating the National Center for Atmospheric Research (NCAR) Advanced Research version of WRF (WRF-ARW; Skamarock et al. 2008) with multiple modeling components and datasets developed at NASA Goddard Space Flight Center (GSFC). WRF-Chem in the NU-WRF, version 8, patch 3, which is based on the WRF-ARW, version 3.7.1, is employed for aerosol transport hindcasts over the target region and periods. The online Goddard Chemistry Aerosols Radiation Transport (GOCART; Chin et al. 2000a,b) bulk aerosol module simulates five major aerosol types (sulfate, dust, black/organic carbon, and sea salt), as well as their precursor gas species.

\section{1) LAND SURFACE AEROSOL EMISSION}

Surface emission of aerosol particles in the GOCART module is derived from prescribed emission inventories and parameterizations, according to the types of emission sources. The emission inventories of anthropogenic sources are based on the global datasets of the monthly 
climatology derived from the Atmospheric Chemistry and Climate Model Intercomparison Project (ACCMIP; Lamarque et al. 2013). Dust emissions are calculated for five particle-size classes using the 10-m height wind speed, the threshold velocity of wind erosion, and the surface conditions, including soil type, ground wetness, topographic depression, and surface bareness (Ginoux et al. 2001; Kim et al. 2017). Biogenic emission rates are functions of the land-use category, air temperature, and solar radiation flux near the surface (Guenther et al. 2006).

Biomass-burning emission data are provided by the global Fire Energetics and Emissions Research version 1.0 product (FEERv1.0; Ichoku and Ellison 2014). The emission databases are spatially interpolated onto the surface grid points of WRF-Chem through the PREP-CHEMSOURCES preprocessing system (Freitas et al. 2011). The method used to introduce the FEER data into PREP-CHEM-SOURCES follows that of the Global Fire Emissions Database (GFED; e.g., Van der Werf et al. 2010).

The FEERv1.0 emission product (Ichoku and Ellison 2014) is derived from the TerralAqua Moderate Resolution Imaging Spectroradiometer (MODIS) daily measurements of FRP. The FRP products are converted to emission rates of sulfur dioxide $\left(\mathrm{SO}_{2}\right)$, dimethyl sulfide (DMS), sulfate, organic/black carbonaceous aerosols, and particles less than 2.5 and $10 \mu \mathrm{m}$ in diameter (PM2.5 and PM10) using emission coefficients derived for each of these species (Ichoku and Ellison 2014). The FEERv1.0-G1.2 product is offered in gridded format at $0.1^{\circ} \times 0.1^{\circ}$ spatial resolution. In addition, the present study also uses a customized FEERv1.0-Mp6 dataset that retains the original $1-\mathrm{km}$ resolution of the native MODIS Collection 6 active fire product (Giglio et al. 2016). This FEERv1.0-Mp6 product maintains the observed coordinates of each fire detection, while also deleting duplicate fire detections resulting from the MODIS bowtie effect at off-nadir locations (Nishihama et al. 1997; Polivka et al. 2016). The FEERv1.0-Mp6 emission product is converted into the gridded data on the NU-WRF domains by accumulating the nongridded emission rates to the nearest model surface grid points.

While biomass burning in West Africa is characterized strongly by a diurnal cycle (e.g., Ichoku et al. 2008), these FEER emission products do not contain information about the diurnal changes of the emission rates. We designed the emission rates of the tracers from biomass burning in the WRF-Chem simulations to diurnally change in the form of a Gaussian function (Roberts et al. 2009). The Gaussian function was characterized by a peak at 1400 local solar time and a full-width at half-maximum (FWHM) value of $2 \mathrm{~h}$ for April and $4 \mathrm{~h}$ for December. These parameters were estimated from climatological analysis of the Fire Radiative Power Gridded (FRPGRID; Wooster et al. 2015; Roberts et al. 2015) product across the
Meteosat coverage region. The emission rates included in the FEERv1.0-Mp6 dataset are currently set to the daily peak values in the Gaussian diurnal cycle, because the Aqua satellite passes over the west coast areas of West Africa usually around 1400 local time. In contrast, the daily peak values in the same Gaussian diurnal cycle are determined from the daily average emission rates in the FEERv1.0-G1.2 dataset to conserve total daily emissions.

\section{2) PARAMETERIZATION OF SMOKE LIFTING EFFECTS ON BIOMASS-BURNING AEROSOL TRANSPORT}

The model design for simulations with 9-km grid spacing follows the parameterization described by Wang et al. (2006) and Yang et al. (2013) and represents the effects of smoke injection on the vertical transport of aerosols emitted from biomass burning. Smoke aerosols are assumed to be mixed uniformly in model vertical levels under fixed injection heights. The injection height is set as $650 \mathrm{~m}$ above ground level (AGL), which is expected to be suitable for simulations for sub-Saharan African biomass burning (Yang et al. 2013). A 1D plume-rise model in the original community version of WRF-Chem (Freitas et al. 2007) is turned off in the present study to prevent double counting the aforementioned processes.

In addition, another parameterization for representing the effects of smoke injection through biomass burning is newly developed and tested in the simulations with $1-\mathrm{km}$ grid spacing. The parameterization is designed to represent the vertical transport of fire-emitted gas and aerosols directly through changes in the dynamic and thermodynamic fields in a model with horizontal resolution of a few kilometers or less, instead of assumptions of a fixed smoke injection height. The forcing to these fields is constrained by the FRP derived from the MODIS fire algorithm products. The detailed descriptions are summarized in the appendix. Chemical tracers released by biomass burning are added into the lowest atmospheric model level and subsequently advected explicitly, when this parameterization is activated.

\section{3) DESIGN OF NUMERICAL EXPERIMENTS}

Figure 1 illustrates the geographical coverage of the NU-WRF WRF-Chem simulation domains. First, 1-month hindcasts were conducted over the entire West Africa domain to explore the synoptic-scale aerosol transport. The model was integrated for the entire months of April and December 2009, from 0000 UTC of the first day to 1200 UTC of the last day of the month. The domain comprised $600 \times 400$ grid points with horizontal grid intervals of $9 \mathrm{~km}$. The vertical levels extending to a top pressure of $50 \mathrm{hPa}$ were divided into 51 layers with intervals increasing with altitude. The FEERv1.0-G1.2 product with $0.1^{\circ} \times 0.1^{\circ}$ 
spatial resolution was used to provide the biomass-burning emission data in the simulations.

Second, a series of 1-day hindcasts were conducted for the small nested domains from 0600 UTC 16 April to 0600 UTC 17 April and similarly for 14-15 December 2009. The domains comprised $729 \times 819$ grid points for 16-17 April and $1044 \times 603$ grid points for 14-15 December with horizontal grid intervals of $1 \mathrm{~km}$. These simulations were designed specifically for testing the new parameterization. The FEERv1.0-Mp6 product with approximately $1-\mathrm{km}$ resolution was employed in these simulations. Offline one-way nesting was applied to embed the meteorological field output from the larger domain simulation in the nested smaller domain simulations. However, the nesting of aerosol/gas fields was turned off, so that the aerosol fields in the 1-day simulations were affected only by the emission within the nested domain to highlight the effects.

The initial and lateral boundary meteorological conditions of the 9-km grid-spacing domain were calculated from global reanalysis datasets with 6-hourly intervals. Three different reanalysis datasets were tested: 1) the Modern-Era Retrospective Analysis for Research and Applications version 2 (MERRA-2; Bosilovich et al. 2015) with a horizontal grid spacing of $0.5^{\circ}$ latitude and $0.625^{\circ}$ longitude, 2) the National Centers for Environmental Prediction (NCEP) Final (FNL) operational global analysis dataset (NOAA/NCEP 2000) with a grid spacing of $1^{\circ}$ in both latitude and longitude, and 3) the interim reanalysis of the European Centre for Medium-Range Weather Forecasts (ECMWF) model (ERA-Interim; Dee et al. 2011) with spectral T255 horizontal resolution. Selection of different meteorological reanalysis datasets may significantly affect the smoke transport simulations (e.g., Ge et al. 2017). Regardless of the selection of the reanalysis for the meteorological fields, the initial and lateral boundary conditions of the aerosol fields for the 1-month simulations with 9-km grid spacing were prepared using MERRA Aerosol Reanalysis (MERRAero; e.g., Buchard et al. 2015) with a horizontal grid spacing of $0.5^{\circ}$ latitude and $0.625^{\circ}$ longitude.

The following physics parameterizations were used in the simulations. The grid-scale cloud microphysics was parameterized using the Goddard Cumulus Ensemble (GCE) single-moment 3-ice bulk microphysics (Lang et al. 2007) interactively with the predicted aerosol mass concentrations (Shi et al. 2014; Tao et al. 2015, 2016). The subgrid cumulus was parameterized using the Grell-3D cumulus parameterization scheme (Grell and Dévényi 2002) only in the simulations with 9-km grid intervals. The Goddard shortwave and longwave radiation schemes, version 2014 (Chou and Suarez 1999, 2001), affected by the aerosol direct effect were used to calculate the

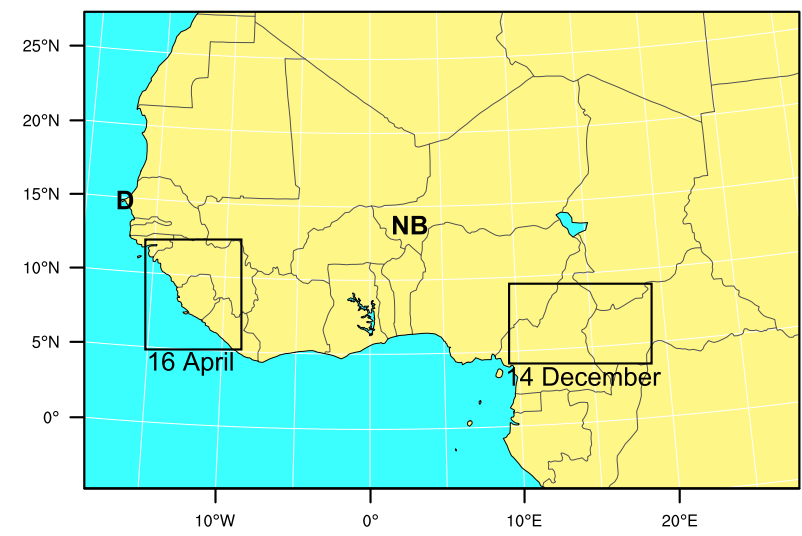

FIG. 1. Domain configuration of the NU-WRF simulations and locations of ground-based measurement sites. The map corresponds to the simulation domain with horizontal grid spacing of $9 \mathrm{~km}$ for 1-month simulations. The areas enclosed by the black squares show the simulation domains with horizontal grid spacing of $1 \mathrm{~km}$ for 1-day simulations. The alphabetical symbols denote the locations of Banizoumbou $\left(\mathrm{B} ; 13.54^{\circ} \mathrm{N}, 2.66^{\circ} \mathrm{E}\right)$, Darkar $\left(\mathrm{D} ; 14.39^{\circ} \mathrm{N}, 16.96^{\circ} \mathrm{W}\right.$ and $\left.14.73^{\circ} \mathrm{N}, 17.5^{\circ} \mathrm{W}\right)$, and Niamey $\left(\mathrm{N} ; 13.48^{\circ} \mathrm{N}, 2.17^{\circ} \mathrm{E}\right)$.

atmospheric radiation (Shi et al. 2014; Lau et al. 2017). The level-2.5 Mellor-Yamada-Nakanishi-Niino turbulence scheme (Nakanishi and Niino 2006, 2009) was chosen for the planetary boundary layer and subgrid-scale turbulence calculation. The unified community Noah land surface model (Tewari et al. 2004) calculated the land surface processes and surface heat fluxes. The simulated horizontal wind fields were further constrained by those in the global reanalysis datasets through spectral nudging (Miguez-Macho et al. 2004) only for the simulations with 9-km grid spacing. The spectral nudging was applied for wavenumbers less than 7 in the $x$ (east-west) direction and 5 in the $y$ (north-south) direction in the simulations, on the basis of our preliminary tests involving comparison with the wind fields in the reanalysis datasets (not shown here).

\section{b. Observation datasets}

Sounding data from the Integrated Global Radiosonde Archive version 2 (IGRA; Durre and Yin 2008) were used to validate the horizontal wind velocities at several pressure levels, which were important factors for determining the aerosol transport. There were multiple active stations of IGRA over West Africa in 2009. However, all stations in West Africa between $5^{\circ}$ and $12^{\circ} \mathrm{N}$, where active biomass burning was mostly observed, had low observation frequencies (S. Nicholls 2017, personal communication). Thus, this study used the sounding data from Niamey, Niger $\left(13.48^{\circ} \mathrm{N}, 2.17^{\circ} \mathrm{E}\right)$, and Dakar, Senegal $\left(14.73^{\circ} \mathrm{N}, 17.5^{\circ} \mathrm{W}\right)$, which had higher observation frequencies, although their locations were outside the forest and savanna zones that were active in biomass burning. These two stations are, in fact, close to Aerosol 
Robotic Network (AERONET; Holben et al. 1998) sites, making them suitable for investigating correlations between the observed horizontal wind patterns and aerosol optical properties at the almost coincident locations.

AERONET provides continuous observations of AOD obtained from ground-based remotely sensed measurements. This study used the daily averages of AERONET level 2.0 (cloud screened and quality assured) AOD products for evaluation of the simulated AOD. The Angström exponent (AE) was calculated from AOD at 440- and 1020-nm wavelengths. Data from the Banizoumbou, Niger $\left(13.54^{\circ} \mathrm{N}, 2.66^{\circ} \mathrm{E}\right)$, and Dakar $\left(14.39^{\circ} \mathrm{N}, 16.96^{\circ} \mathrm{W}\right)$ sites were explored because of their closeness to active biomass-burning zones and better observation frequencies.

The following satellite products provide horizontal distributions of monthly AOD and AE: Sea-Viewing Wide Field-of-View Sensor (SeaWiFS) Deep Blue Level 3 global gridded $\left(0.5^{\circ} \times 0.5^{\circ}\right)$ version-4 data (Hsu et al. 2012, 2013) of AOD at 550-nm wavelength and AE, the Terral Aqua MODIS Collection 6 Level 3 monthly gridded atmosphere product AOD at $550 \mathrm{~nm}$ (the Dark Target and Deep Blue algorithms merged; $0.5^{\circ} \times 0.5^{\circ}$ ) and AE (Deep Blue algorithm for land only; $1^{\circ} \times 1^{\circ}$ ) (Sayer et al. 2014; Levy et al. 2015), and the Terra Multiangle Imaging SpectroRadiometer (MISR) Level 3 global aerosol product $\left(0.5^{\circ} \times 0.5^{\circ}\right)$ version- 4 AOD at $555 \mathrm{~nm}$ and AE (MISR Science Team 2015). These satellite products were used to explore the horizontal variability of column aerosol optical properties in April and December 2009. Total attenuated backscatter at $532 \mathrm{~nm}$ and aerosol subtype classification in the CALIPSO retrieval products, version 4.10 (Omar et al. 2009; Winker et al. 2009; CALIPSO Science Team 2015), were used as references for the vertical profiles of aerosol structure in the discussion.

\section{Results}

\section{a. One-month simulations with 9-km grid spacing for April and December 2009}

Active biomass-burning locations and FRP were quite different between April and December 2009. Figure 2 shows the distributions of fire locations and their respective FRP values, as extracted from the TerralAqua MODIS Collection 5 active fire product (Giglio 2013) for these two months. The observed FRP is correlated with the biomassburning rates of combustion and smoke emission (e.g., Ichoku and Kaufman 2005; Wooster et al. 2005).

In April 2009 (Fig. 2a), fire detections with per-pixel FRPs higher than $450 \mathrm{MW}$ were mainly concentrated in a limited region near the west coast of West Africa, where they are distributed roughly across Guinea, Sierra
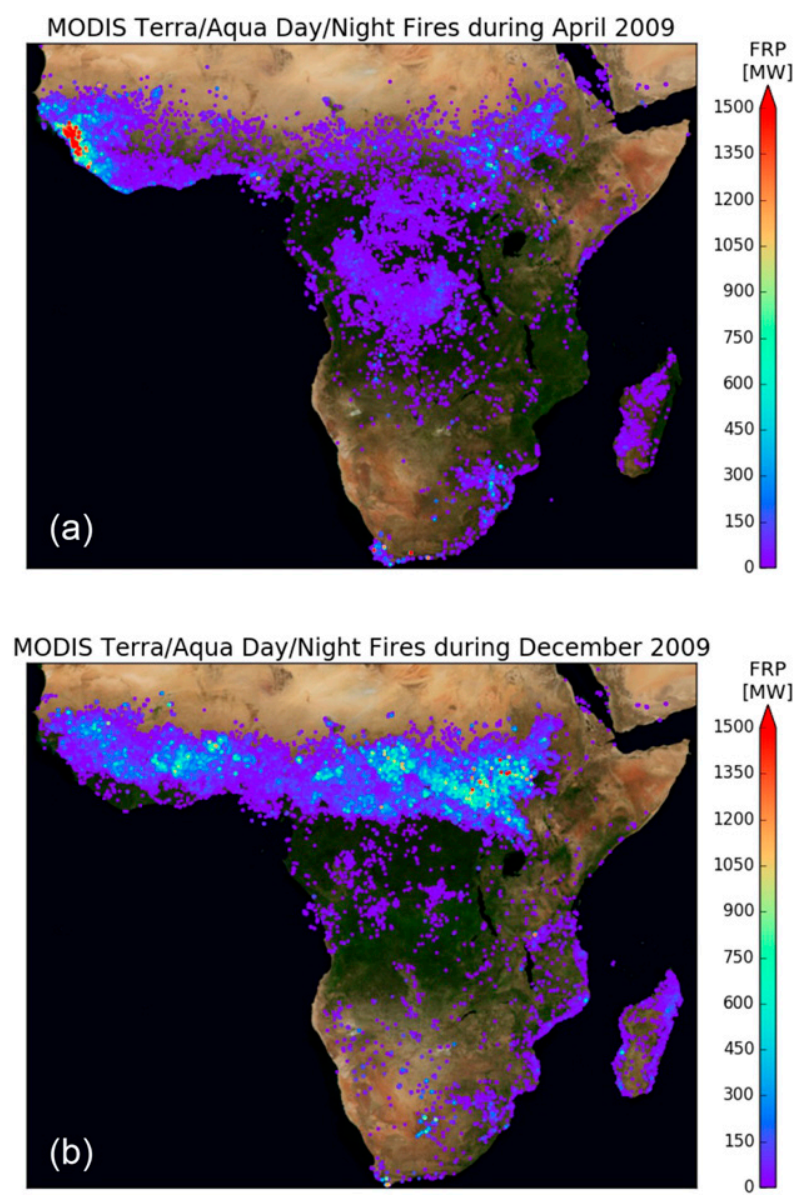

FIG. 2. Monthly fire locations and composited FRP (MW) derived from the TerralAqua MODIS Collection 5 Active Fire Product during (a) April and (b) December 2009.

Leone, and Liberia. Outside of these high-FRP locations, fire locations with FRPs lower than $150 \mathrm{MW}$ are widely distributed across West and Central Africa. The FRP distribution in December 2009 (Fig. 2b) is quite different from that of April 2009. Fires with FRPs higher than $150 \mathrm{MW}$ are widely distributed, mostly across the savanna, cropland, and grassland belts of West and Central Africa, although its local maximum is less prominent than that of April 2009. Pixel FRP values of around $750 \mathrm{MW}$ were observed over a wide area in the northern part of Central Africa. Because the African easterly jet (AEJ; e.g., Berry et al. 2007) is dominant in the northern tropical latitudes of Africa, aerosol particles emitted from these areas are generally transported through West Africa and affect the air quality there.

\section{1) COMPARISON WITH SATELLITE-RETRIEVED AEROSOL DISTRIBUTIONS}

Figure 3 shows the monthly AOD and AE distributions from the satellite gridded aerosol products in April 2009 
(a) SeaWiFS monthly AOD in April 2009

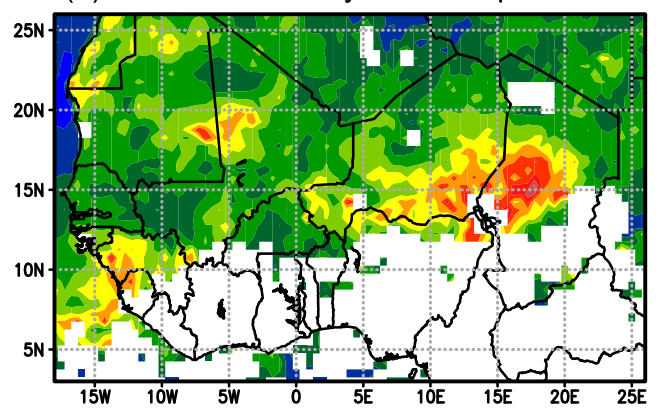

(b) TerraMODIS monthly AOD in April 2009

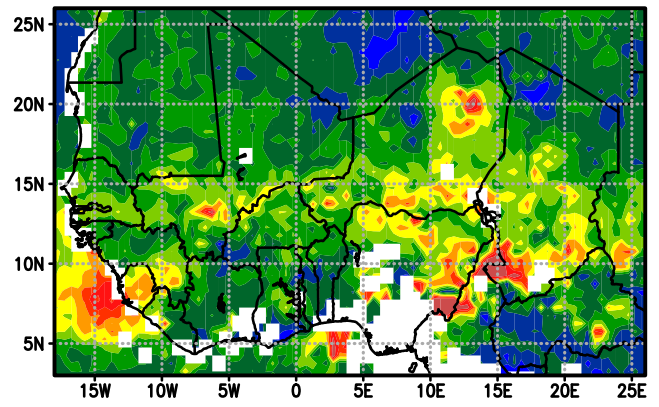

(c) AquaMODIS monthly AOD in April 2009

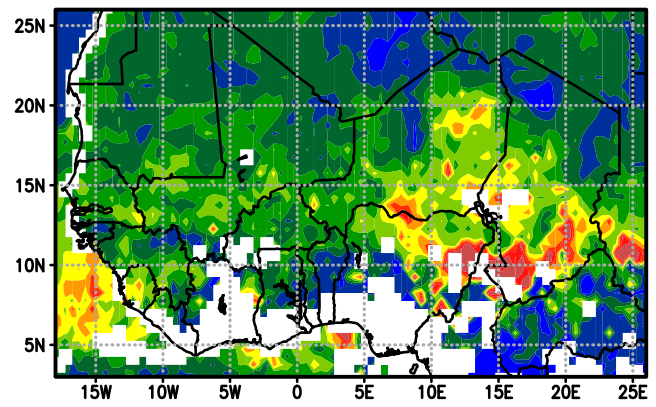

(d) MISR monthly AOD in April 2009

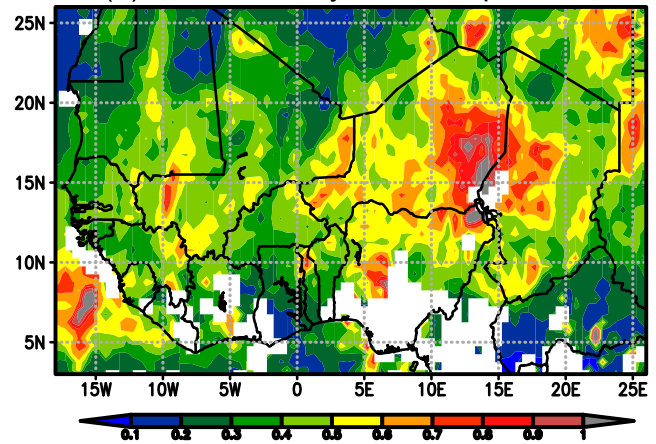

(e) SeaWiFS monthly AE in April 2009

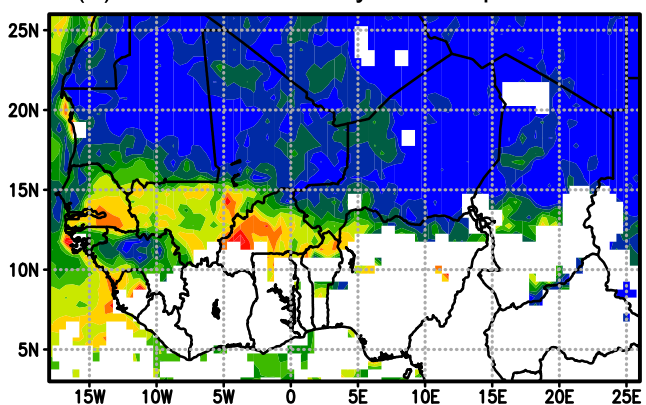

(f) TerraMODIS monthly AE in April 2009

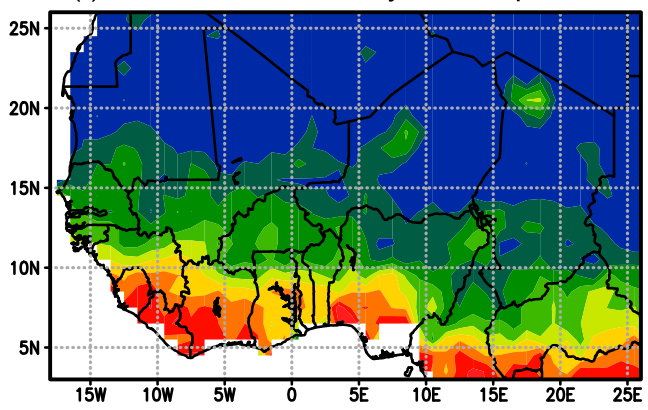

(g) AquaMODIS monthly AE in April 2009

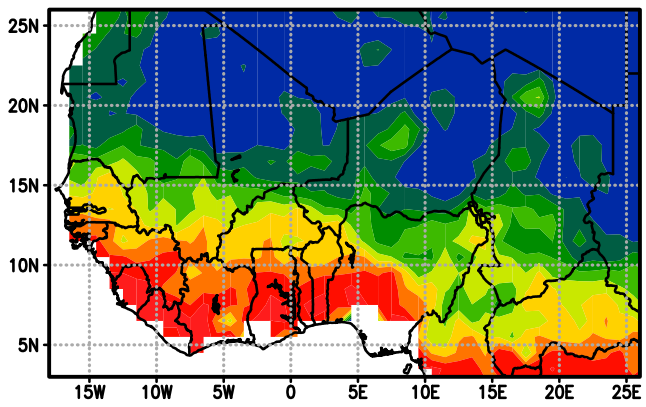

(h) MISR monthly AE in April 2009

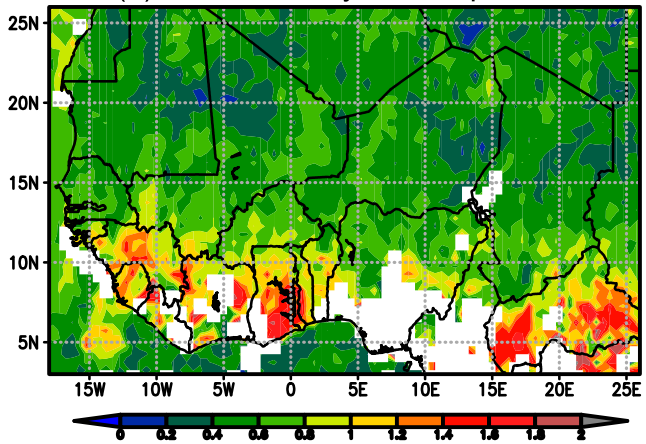

FIG. 3. Monthly (left) AOD at 550- or 555-nm wavelengths and (right) AE during April 2009 from (a),(e) SeaWiFS Deep Blue Level 3 global gridded version-4 data, (b),(f) Terra and (c),(g) Aqua MODIS Collection 6 Level 3 monthly gridded atmosphere products, and (d),(h) MISR Level 3 global aerosol product version-4 data.

over the WRF simulation domain with 9-km grid spacing. Overland AOD higher than 0.5 was observed over the west coast of sub-Saharan West Africa and multiple areas of the eastern Sahara. The overland AE distributions show a clear contrast between the north and the south around $10^{\circ} \mathrm{N}$. The high AODs over the eastern Sahara are coincident with lower AE, and they are due to high concentrations of mineral dust aerosol particles with relatively large particle sizes. In contrast, the high AODs over the west coast of West Africa are due to smaller 
(a) NU-WRF MERRA-2 monthly AOD in April

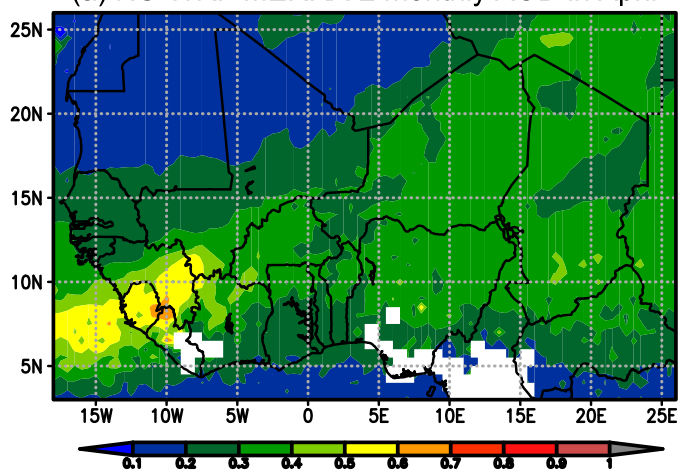

(b) NU-WRF FNL monthly AOD in April

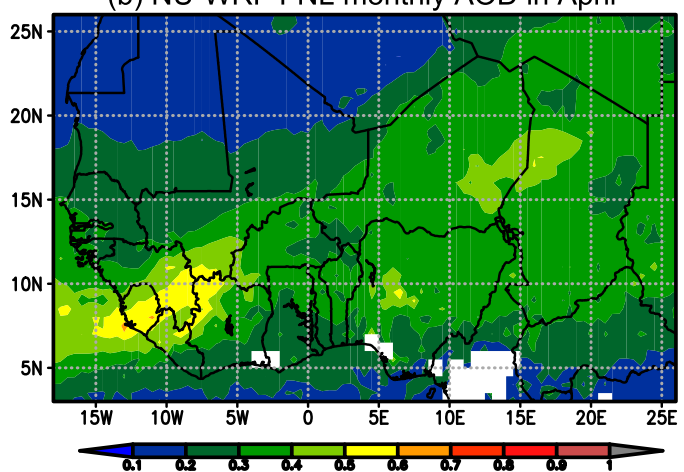

(c) NU-WRF Interim monthly AOD in April

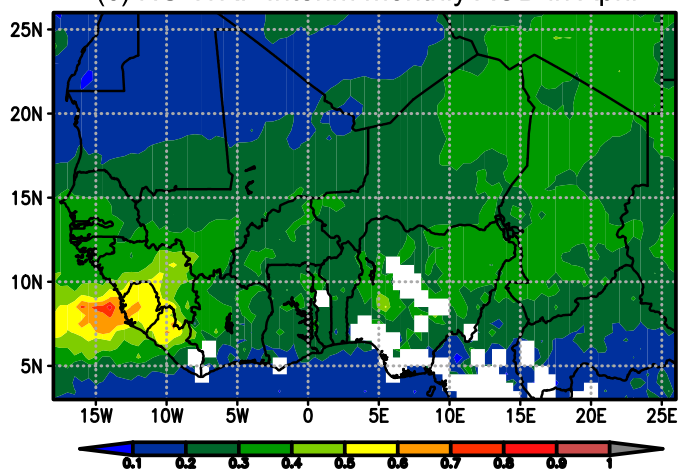

(d) NU-WRF MERRA-2 monthly AE in April

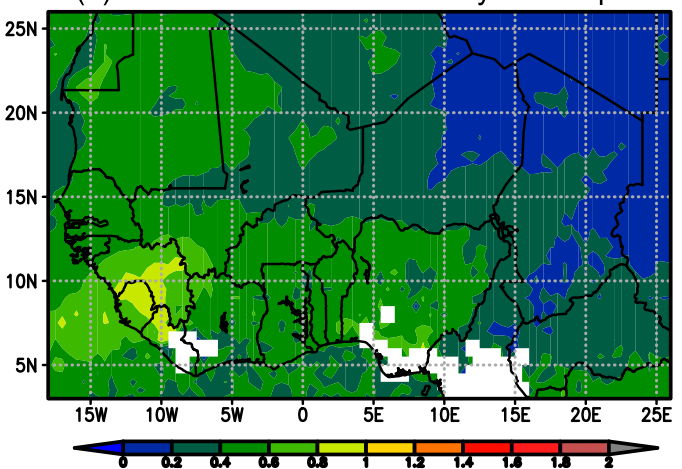

(e) NU-WRF FNL monthly AE in April

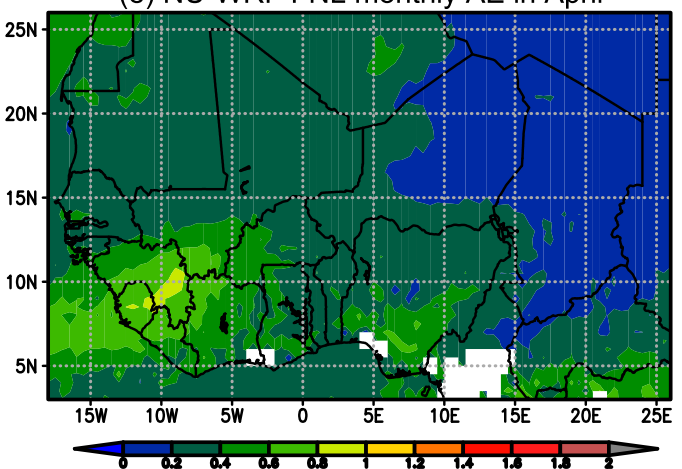

(f) NU-WRF Interim monthly AE in April

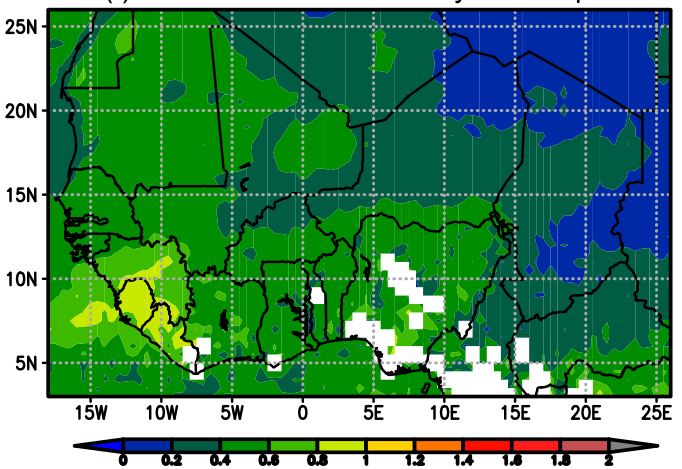

FIG. 4. Monthly (left) cloudless-sky AOD at a visible band (400-700 nm) and (right) AE during April 2009, calculated from the NU-WRF simulation results using the forcing reanalysis data: (a),(d) MERRA-2, (b),(e) FNL, and (c),(f) ERA-Interim.

smoke aerosol particles emitted from biomass burning, because they are coincident with higher AE. The presence of active biomass burning over the region is clearly shown by the observed high FRP in Fig. 2 a.

The observed monthly AOD and AE values in Fig. 3 for April 2009 are compared with those calculated from the WRF-Chem simulations. Figure 4 illustrates the distribution of monthly cloudless-sky AODs at a visible band $(400-700 \mathrm{~nm})$ and their corresponding AE. The monthly AODs and AEs were calculated as an average of values at every 1200 UTC only under cloudless-sky conditions defined as cloud optical depth (COD) less than 1 . Overall, the simulations with the three different forcing datasets underpredicted AOD similarly. However, the spatial patterns of relative magnitudes in these simulated AODs are roughly similar to those in the observed AOD in Fig. 3. In particular, all simulated distributions show higher AOD at $5^{\circ}-10^{\circ} \mathrm{N}$ and $15^{\circ}-10^{\circ} \mathrm{W}$, which is caused by smoke aerosols from biomass burning near this location. In contrast, the 
(a) SeaWiFS monthly AOD in December 2009

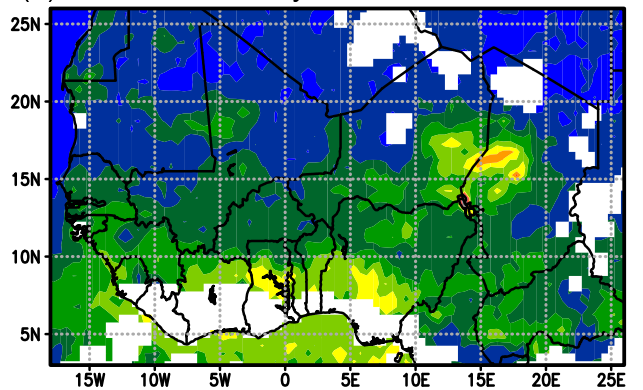

(b) TerraMODIS monthly AOD in Decebmer 2009

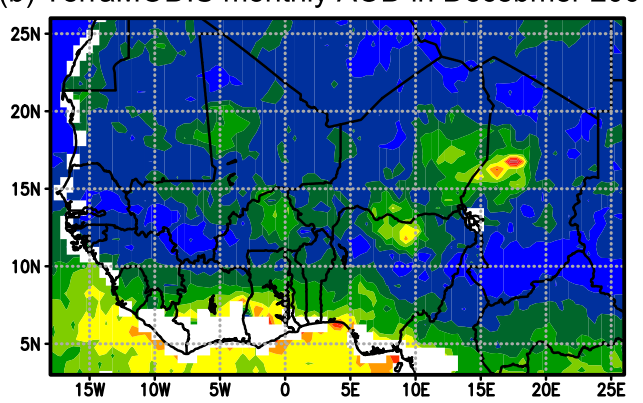

(c) AquaMODIS monthly AOD in December2009

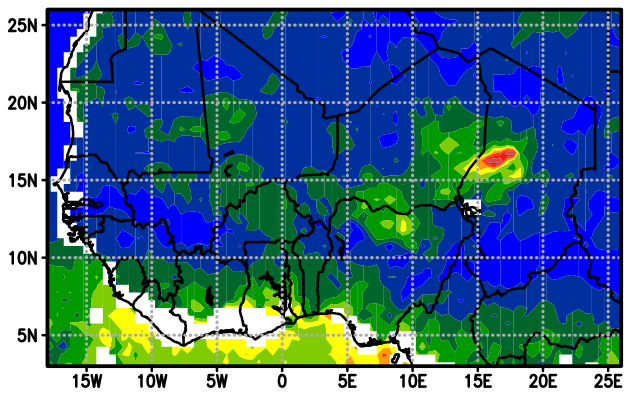

(d) MISR monthly AOD in December 2009

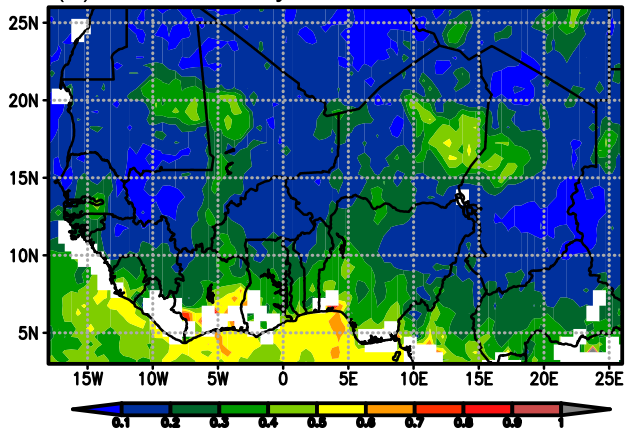

(e) SeaWiFS monthly AE in December 2009

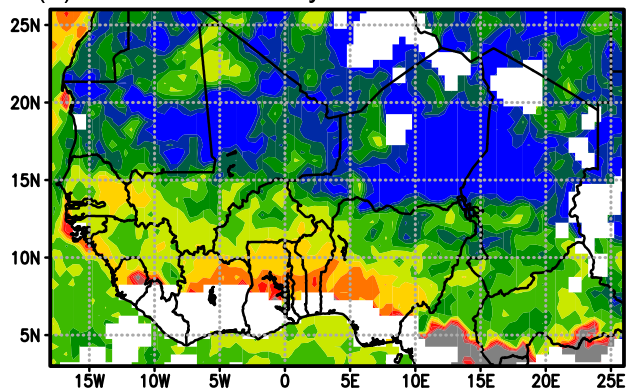

(f) TerraMODIS monthly AE in December 2009

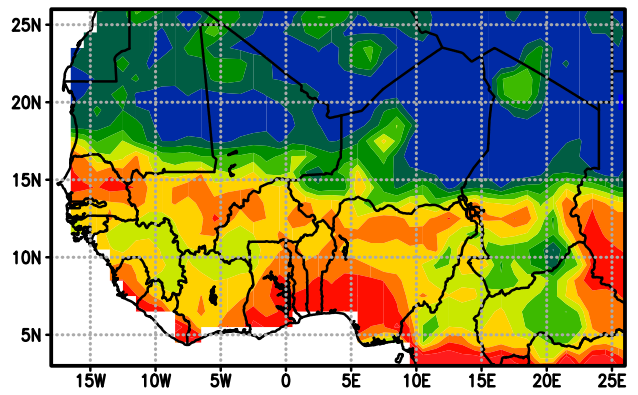

(g) AquaMODIS monthly AE in December 2009

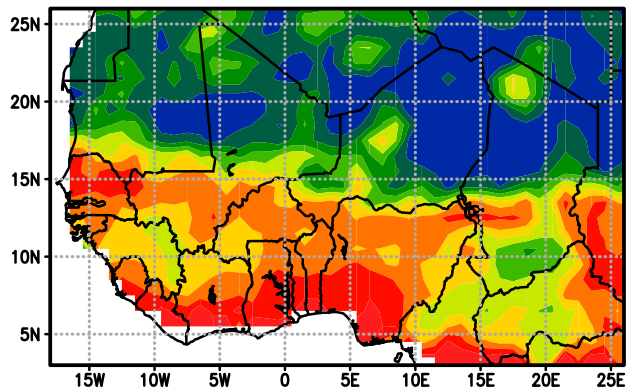

(h) MISR monthly AE in December 2009

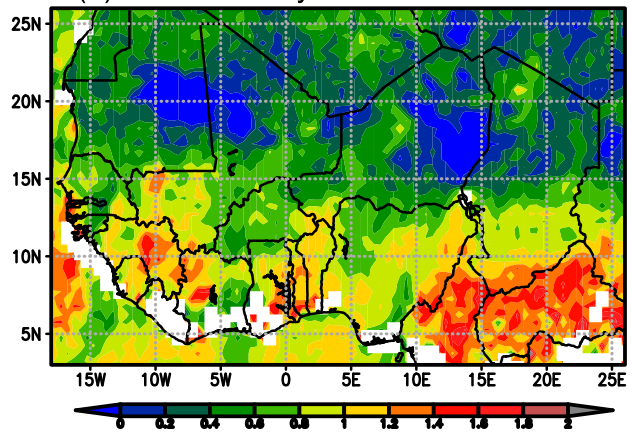

FIG. 5. As in Fig. 3, but for December 2009.

simulations significantly underpredicted AOD due to dust aerosols over the eastern Sahara, although the simulation driven by FNL shows a peak of AOD around $15^{\circ} \mathrm{N}$ and $15^{\circ} \mathrm{E}$. Overall, the three simulations show similar weak gradients of AE from the southeast to the northwest of the domain. The observed overland AE is underpredicted, especially over the southern parts of the domain, regardless of the forcing data selection.
The monthly AOD in December 2009 from the satellite products (Fig. 5) was generally lower than the corresponding April AOD (Fig. 3) throughout the domain. Relatively high AOD was widely distributed in the coastal and inshore areas of sub-Saharan West Africa and in a limited area of the Sahara. The high AOD over subSaharan West Africa appears to be attributable to the production of smoke aerosols due to active biomass 
(a) NU-WRF MERRA-2 monthly AOD in Dec

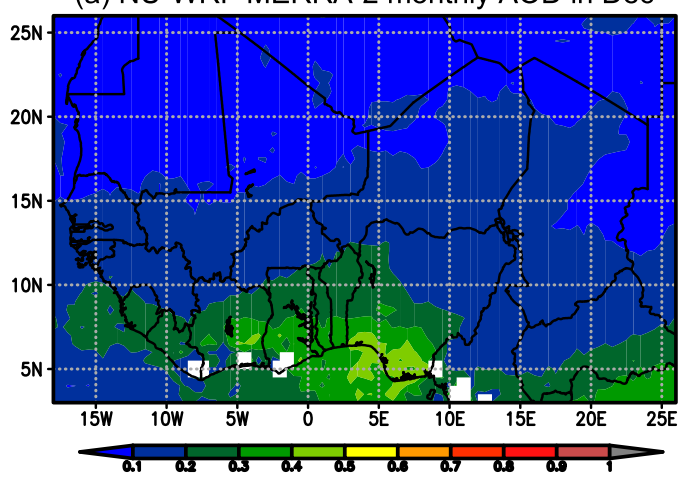

(b) NU-WRF FNL monthly AOD in Dec

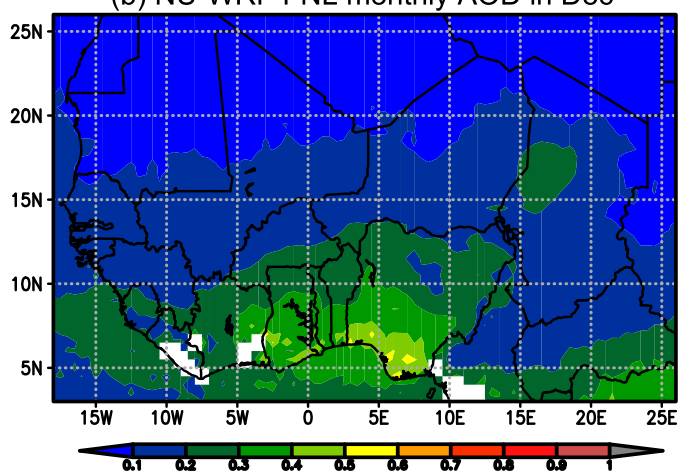

(c) NU-WRF Interim monthly AOD in Dec

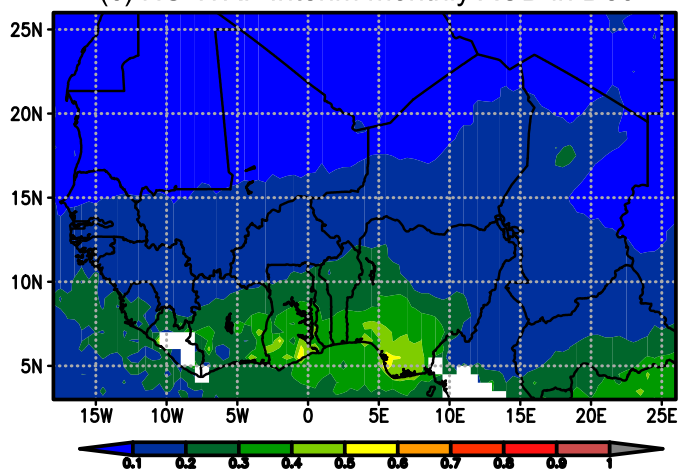

(d) NU-WRF MERRA-2 monthly AE in Dec

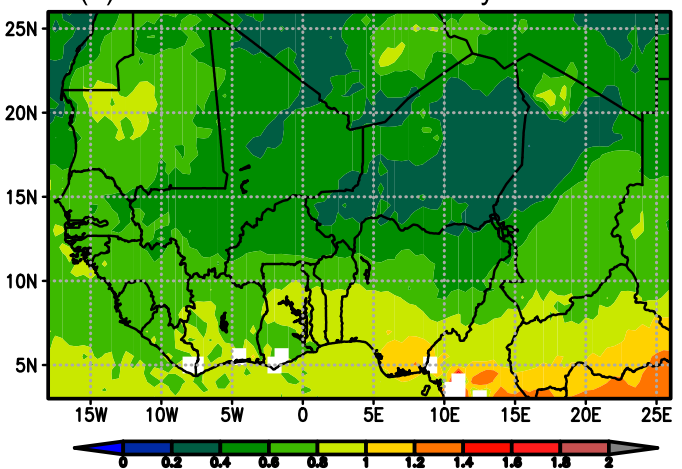

(e) NU-WRF FNL monthly AE in Dec

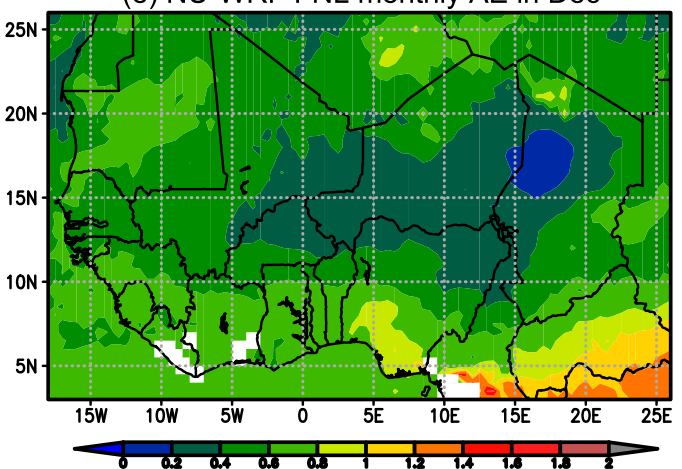

(f) NU-WRF Interim monthly AE in Dec

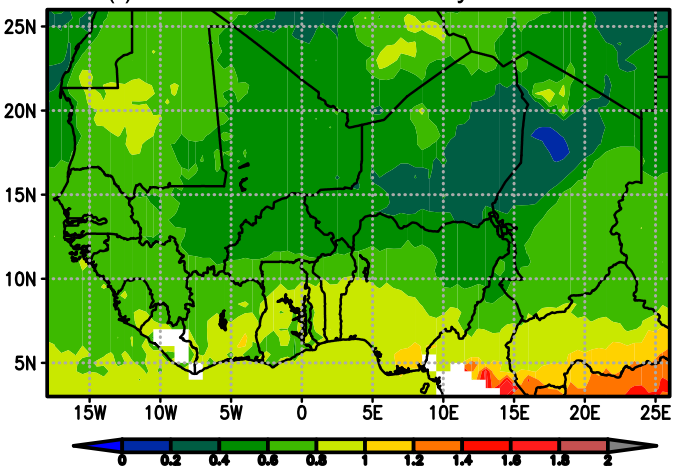

FIG. 6. As in Fig. 4, but for December 2009.

burning over the region and during the month (Fig. 2b). The distribution of AE in December 2009 (Fig. 5) was generally similar to that in April 2009 (Fig. 3), which indicates similar aerosol subtype distributions during these months.

Figure 6 shows the simulated cloudless-sky AOD and AE in December 2009 for comparison with those in Fig. 5. Overall, the three simulations reproduced similar spatial patterns to that of the observed AOD, but underpredicted the AOD throughout the domain. Because high AOD south of $10^{\circ} \mathrm{N}$ is close to higher FRP in Fig. $2 \mathrm{~b}$, the high AOD is attributed to high concentrations of smoke aerosols from biomass burning. North of $15^{\circ} \mathrm{N}$, the underprediction of AOD is insignificant, although the observed local maximum near $15^{\circ} \mathrm{N}$ and $15^{\circ} \mathrm{E}$ is not well simulated. The spatial patterns of relative magnitudes of AE between the observation and the simulation are similar.

The April and December simulations share some characteristics in simulating the monthly AOD and AE results against the satellite measurement products. All simulations tended to underpredict AOD, especially over the eastern Sahara, where mineral dust aerosols are dominant. The spatial patterns of relative magnitudes of AOD were generally simulated correctly, particularly 

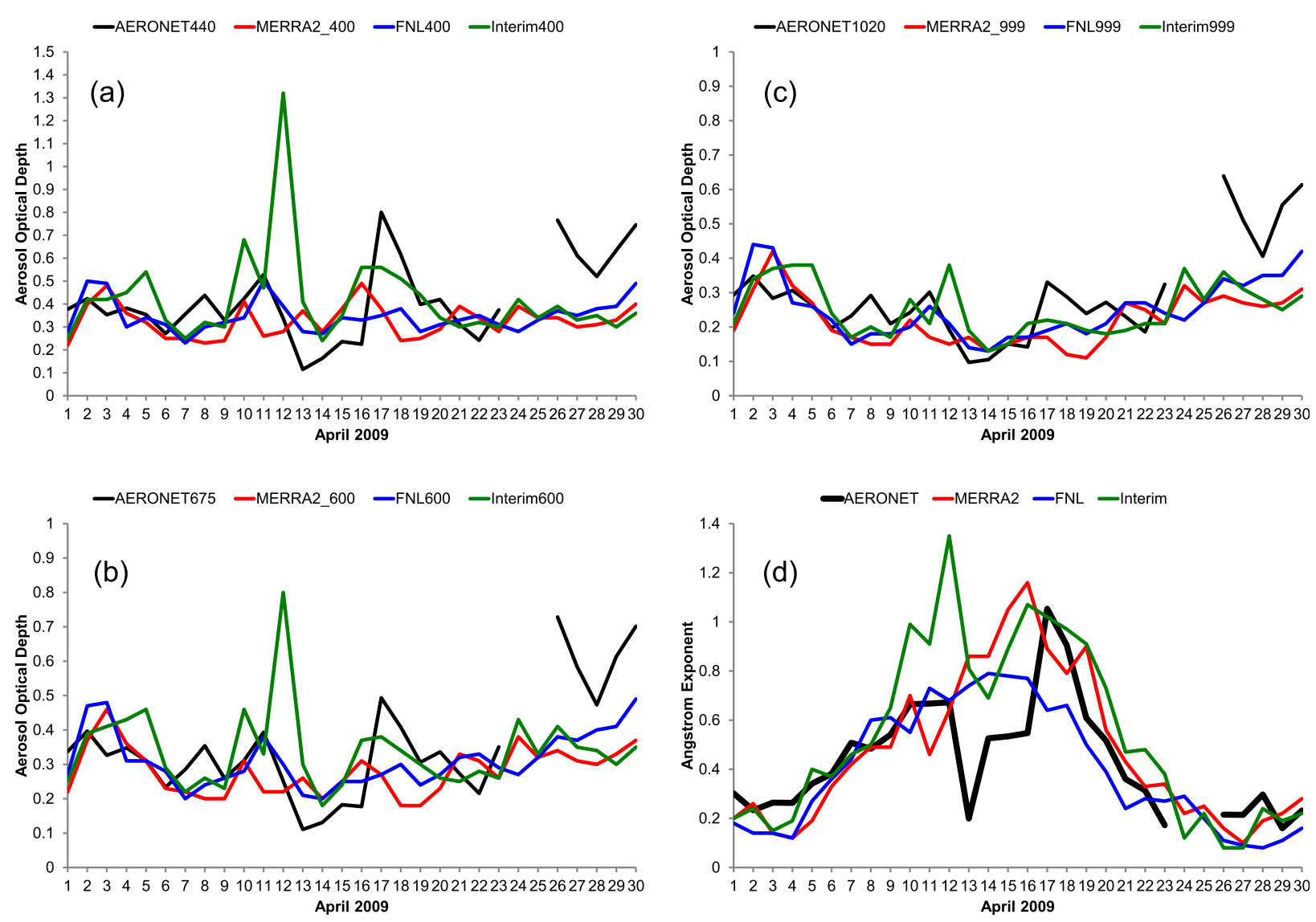

FIG. 7. Monthly cycles of daily (a)-(c) AOD and (d) AE at Dakar $\left(14.39^{\circ} \mathrm{N}, 16.96^{\circ} \mathrm{W}\right)$ during April 2009, derived from AERONET level 2.0 AOD products and the NU-WRF simulation results using the forcing reanalysis data: MERRA-2, FNL, and ERA-Interim. The simulated AODs at 400-, 600-, and 999-nm wavelengths in (a)-(c), respectively, are compared with the observed AODs at wavelengths of $440 \mathrm{~nm}$ in (a), $675 \mathrm{~nm}$ in (b), and $1020 \mathrm{~nm}$ in (c). The observed AODs are a daily average from more than three observations in a day, while simulated values are sampled at every 1200 UTC.

around sub-Saharan West Africa close to active biomassburning areas in each month. The simulations also similarly underpredicted AE, especially over sub-Saharan West Africa south of $10^{\circ} \mathrm{N}$. These biases of AOD and AE may be attributed to the different uncertainties in the satellite aerosol products (Wang et al. 2018). To further evaluate the model, the simulated aerosol optical properties are compared with the AERONET measurements in the next section.

\section{2) COMPARISON WITH AERONET AND IGRA SONDE MEASUREMENTS}

Day-to-day variations of AOD and AE are evaluated by comparing daily values obtained from the AERONET ground-based measurements and the simulation results. The observation and simulation data at the AERONET sites in Dakar $\left(14.39^{\circ} \mathrm{N}, 16.96^{\circ} \mathrm{W}\right)$ in April 2009 and Banizoumbou $\left(13.54^{\circ} \mathrm{N}, 2.66^{\circ} \mathrm{E}\right)$ in December 2009 are discussed below, because the locations were close to active biomass-burning areas during those months (Figs. 1 and 2).

Figure 7 shows the time series of daily AOD and AE at Dakar during April 2009, obtained from the AERONET measurements and the WRF-Chem simulations. The AERONET AODs at 440- and 675-nm wavelengths show local maxima around 11,17 , and 26-30 April in Fig. 7. The observed high AOD around 11 and 17 April was coincident with the relatively high AE in Fig. 7d, whereas AE was very low for 26-30 April. The increased observed AOD in the middle of the month was caused mostly by the increased concentration of smaller aerosol particles, which are probably aerosols from biomass burning. In contrast, the increased AOD simultaneously with decreased AE for 26-30 April was due to an increased concentration of larger-size aerosol particles (i.e., mineral dust).

The simulations in Fig. 7 show different AOD values at 440 and $675 \mathrm{~nm}$ on 12 April and around 16 April. 
(a) NU-WRF MERRA-2 AOD 12UTC 12 April

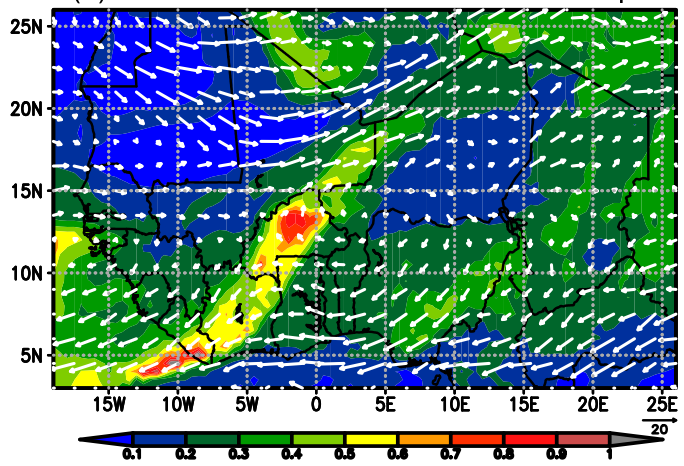

(b) NU-WRF FNL AOD 12UTC 12 April

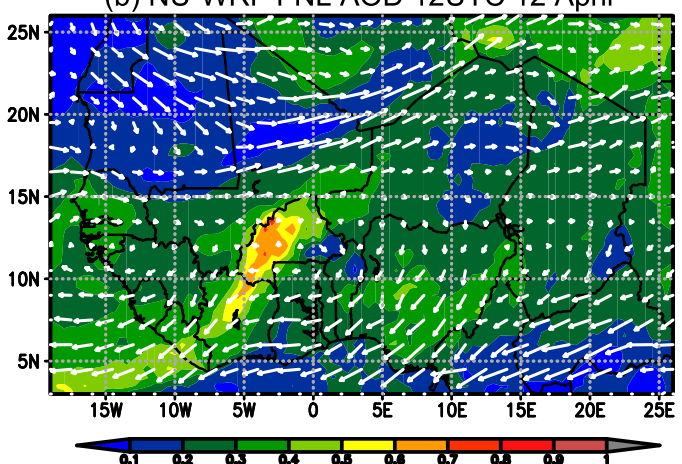

(c) NU-WRF Interim AOD 12UTC 12 April

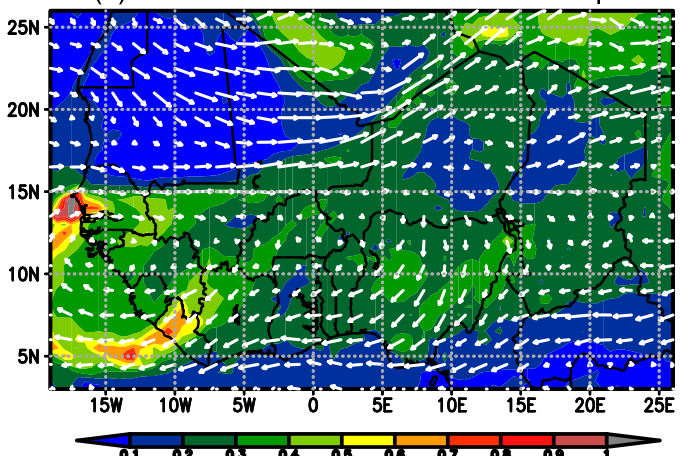

(d) NU-WRF MERRA-2 AOD 12UTC 16 April

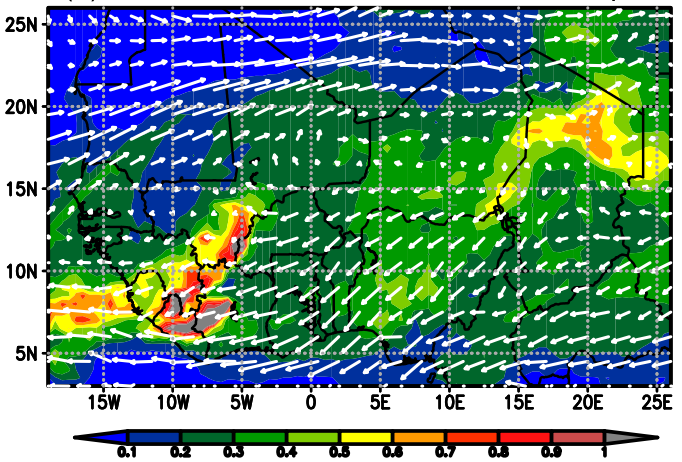

(e) NU-WRF FNL AOD 12UTC 16 April

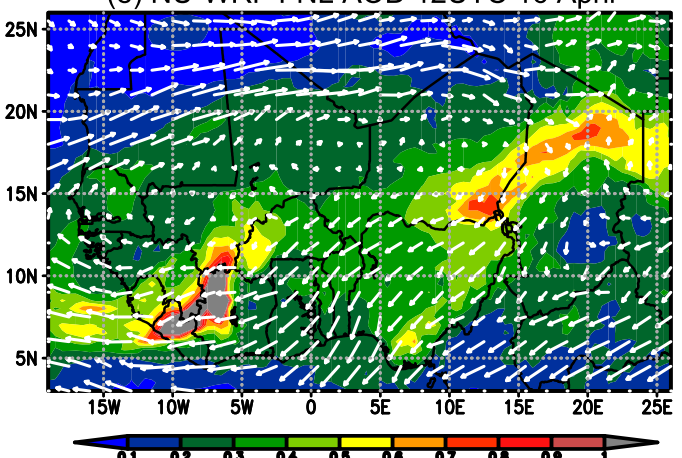

(f) NU-WRF Interim AOD 12UTC 16 April

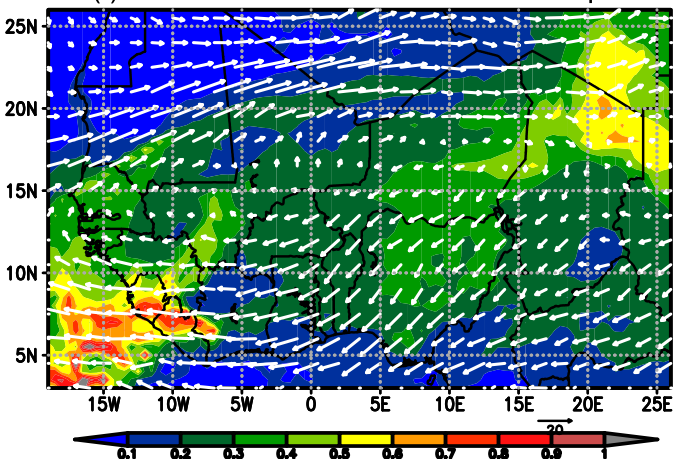

FIG. 8. Horizontal distribution of AOD at a visible band (400-700-nm wavelength) with 700-hPa horizontal wind vectors overlaid at 1200 UTC (left) 12 and (right) 16 Apr 2009, simulated by the NU-WRF simulations using the forcing reanalysis data: (a),(d) MERRA-2, (b),(e) FNL, and (c),(f) ERA-Interim.

In particular, the simulation driven by ERA-Interim yielded significantly large AOD in comparison with the other simulations and the observed AOD on 12 April. To investigate the different AODs at Dakar, the horizontal distribution of the simulated AOD and horizontal wind fields at the 700-hPa pressure level at 1200 UTC 12 and 16 April are shown in Fig. 8. Anticyclonic circulations were present in the southwestern part of the domain on both days in all simulations. High AOD was simulated along parts of the rim of the anticyclonic circulation. This high AOD is caused by biomass-burning aerosols, which has been confirmed by a sensitivity simulation that turns off the emission of biomass-burning aerosols (the result is not shown here). The locations and magnitudes of the simulated anticyclonic circulations vary according to the selection of the forcing reanalysis dataset (MERRA-2, FNL, and ERA-Interim). As a result, the distributions of the simulated AODs are different. In the simulation driven by ERA-Interim (Fig. 8c), an air mass with very high AODs advected 
(a) Zonal Wind ( $\mathrm{m} / \mathrm{s})$ at Dakar in April 2009

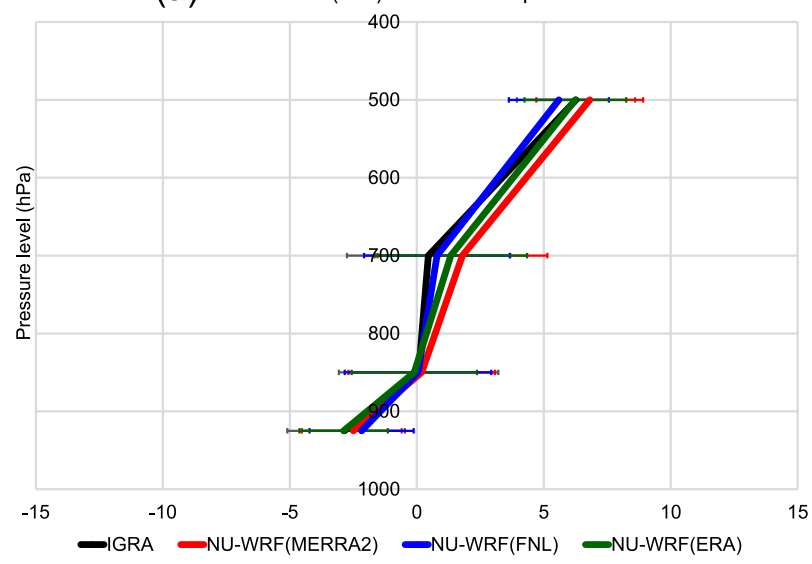

(b) Meridional Wind ( $\mathrm{m} / \mathrm{s})$ at Dakar in April 2009

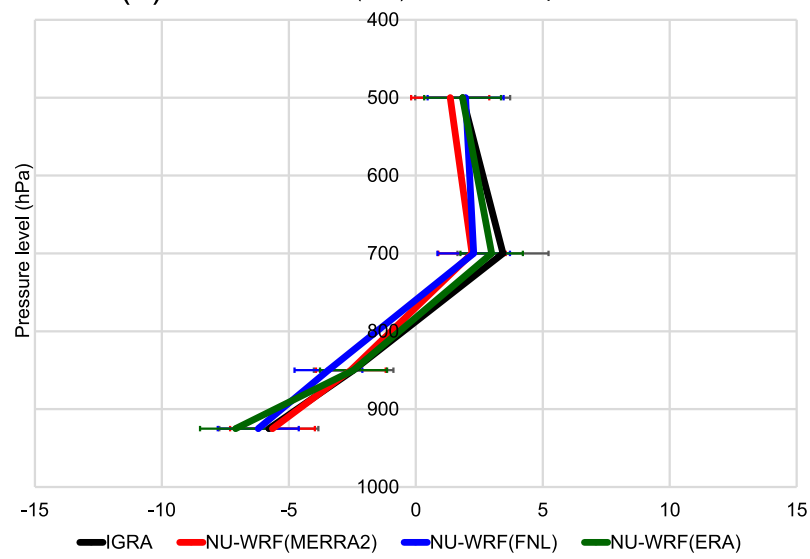

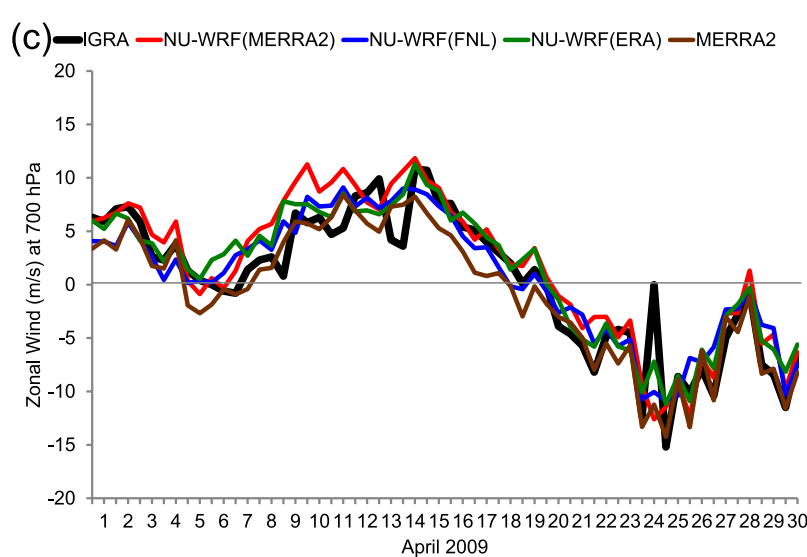

$(d) \underset{15}{-}$ GRA $-N U-W R F(M E R R A 2)$-NU-WRF(FNL) $-N U-W R F(E R A)$-MERRA2

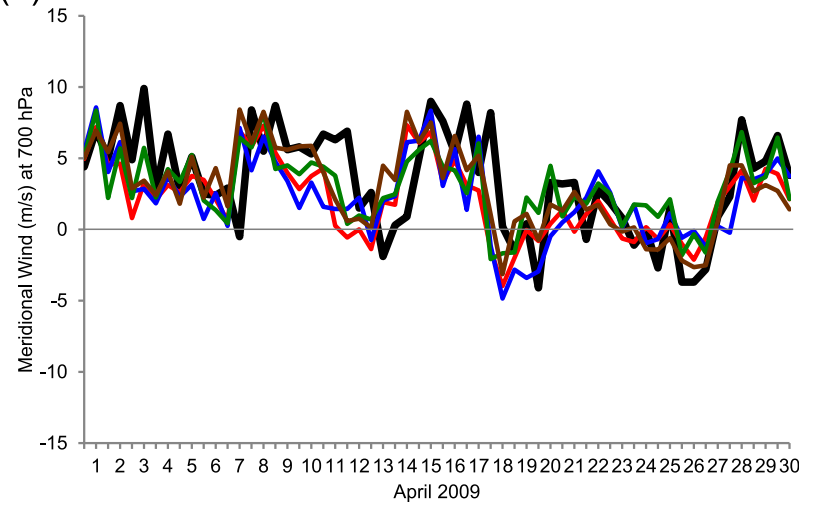

FIG. 9. (a),(b) Monthly averages and standard deviation of the zonal and meridional wind components ( $\mathrm{m} \mathrm{s}^{-1}$ ) at Dakar during April 2009, from IGRA V2 sounding data and NU-WRF simulation results using the forcing reanalysis data: MERRA-2, FNL, and ERAInterim. (c),(d) Monthly cycles of the zonal and meridional wind components at 700-hPa pressure level at every 0000 and 1200 UTC, together with those from the MERRA-2 original data.

by a southwesterly wind from the ocean hit Dakar on 12 April. This caused the significantly large AODs at 440 and $675 \mathrm{~nm}$ at Dakar on 12 April in the monthly cycle (Fig. 7). The other simulations (Figs. 8a,b) do not show such a significant increase of AOD, because the simulated high AODs swerved slightly away from Dakar. However, an effect of the advection of biomass-burning aerosols was seen in the simulated AE monthly cycle at Dakar (Fig. 7d), regardless of the selection of the reanalysis. The simulated AE in the middle of the month is higher than those in the beginning and end of the month. The day-to-day variations of the simulated AEs are in broad agreement with those in the observations.

Figures $9 \mathrm{a}$ and $9 \mathrm{~b}$ illustrate the monthly averages and standard deviations of the zonal and meridional wind components at the 925-, 850-, 700-, and 500-hPa pressure levels at the Dakar IGRA site in April 2009. The vertical profiles show a strong wind shear under the $700-\mathrm{hPa}$ level, especially in the meridional wind component. Overall, the simulated horizontal wind components agree with those of the observations as a result of the spectral nudging. Figures $9 \mathrm{c}$ and $9 \mathrm{~d}$ illustrate variations of the observed and simulated zonal/meridional wind components every $12 \mathrm{~h}$ at the $700-\mathrm{hPa}$ level at the Dakar site in April 2009. This comparison between observed and simulated horizontal wind components is used to further explore the day-to-day variations of the aerosol optical properties in the AERONET measurements and the simulations shown in Fig. 7. The fluctuation patterns of the observed wind components at the $700-\mathrm{hPa}$ level (Fig. 9) are broadly correlated with those of the observed AE in Fig. 7d. Thus, the observed higher AE around 11 and 17 April are coincident with the southwesterly wind (large positive zonal and meridional components) in Fig. 9, and a momentary decrease in the observed AE on 13 April is coincident with a temporal 

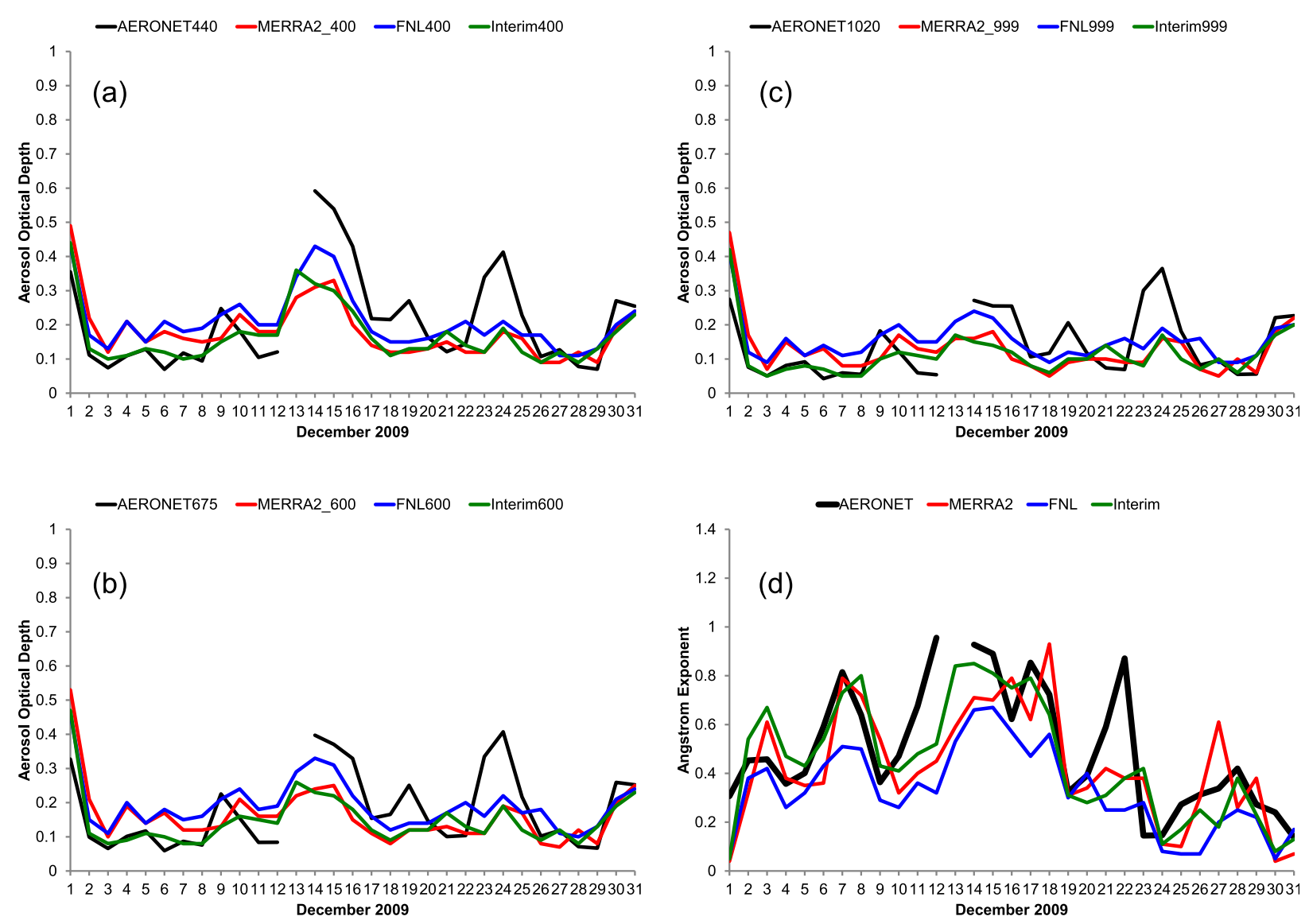

FIG. 10. As in Fig. 7, but at Banizoumbou during December 2009.

wind change around the same day. In contrast, an easterly wind (negative zonal wind) is dominant in the latter part of the month, and simultaneously the observed AE is relatively low.

The simulated horizontal wind components are in general agreement with those in the observations in Figs. 9c and 9d. A southwesterly wind is continuously simulated in the middle of the month, similarly to that in the observed day-to-day variation. How the southwesterly wind contributed to the increase of AE at Dakar through advection of biomass-burning aerosols is demonstrated in Fig. 8. However, none of the simulations captured the momentary change in the observed horizontal wind around 13 April. This prediction error could lead to the abrupt decrease in the observed $\mathrm{AE}$ on 13 April being missed (Fig. 7d).

Figure 10 shows the time series of daily AOD and AE at Banizoumbou during December 2009, obtained from the AERONET measurements and the simulations. The observed AOD at $440 \mathrm{~nm}$ was highest on 14 December, while AODs at the other three wavelengths on that same day were clearly lower. The significantly higher
AOD at $440 \mathrm{~nm}$ is due to high concentrations of smaller aerosol particles, which is also reflected in the relatively high AE on the same day. The time series of the simulated AOD and AE results at Banizoumbou in December 2009 agree generally with those in the observations in Fig. 10, except from 20 to 26 December. The day-to-day variations of both observed and simulated AODs, particularly at 440- and 400-nm wavelengths, show a local maximum in the middle of the month. This local maximum of AOD around 14 December is collocated with a local maximum of $\mathrm{AE}$ in both the observations and simulations.

Figure 11 illustrates the same analysis on the horizontal wind components as in Fig. 9 but at the Niamey IGRA site during December 2009. The vertical profiles of the averaged zonal wind in Fig. 11a suggest that a weak easterly wind was generally dominant at each pressure level, whereas the averaged meridional wind is slightly northerly. Overall, the simulations reproduced the vertical profiles of the observed wind components as well as the day-to-day variations of the observed zonal and meridional wind at $700 \mathrm{hPa}$ in Figs. 11c and 11d. 
(a) Zonal Wind $(\mathrm{m} / \mathrm{s})$ at Niamey in December 2009
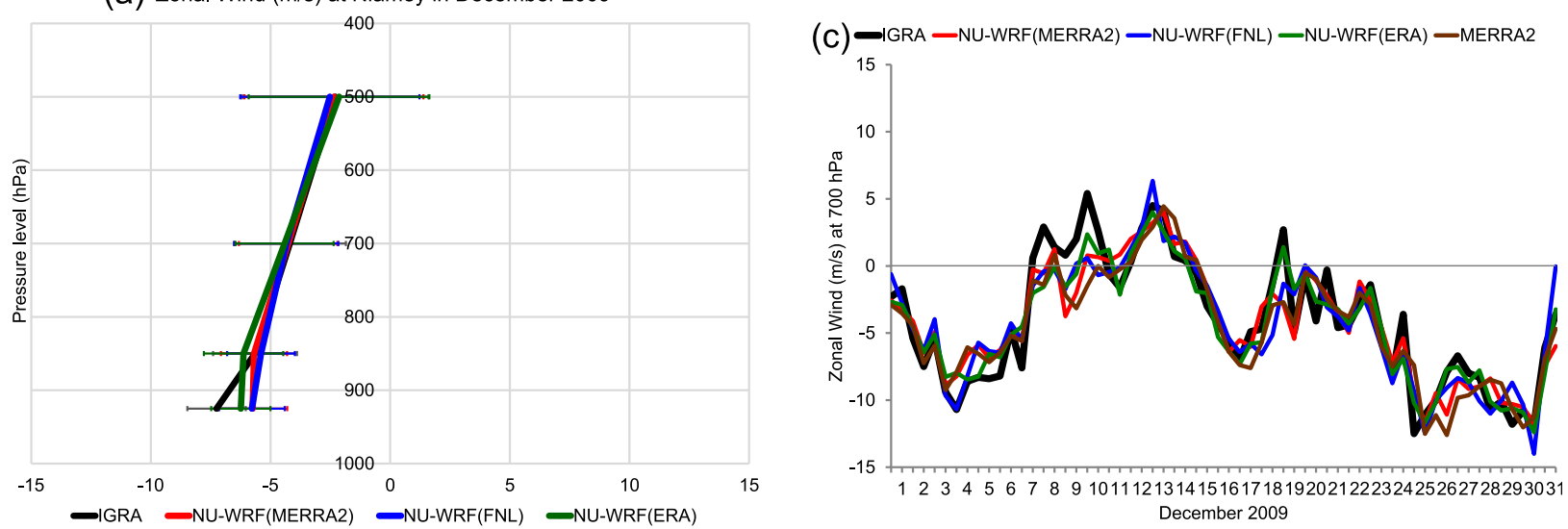

(b) Meridional Wind ( $\mathrm{m} / \mathrm{s}$ ) at Niamey in December 2009
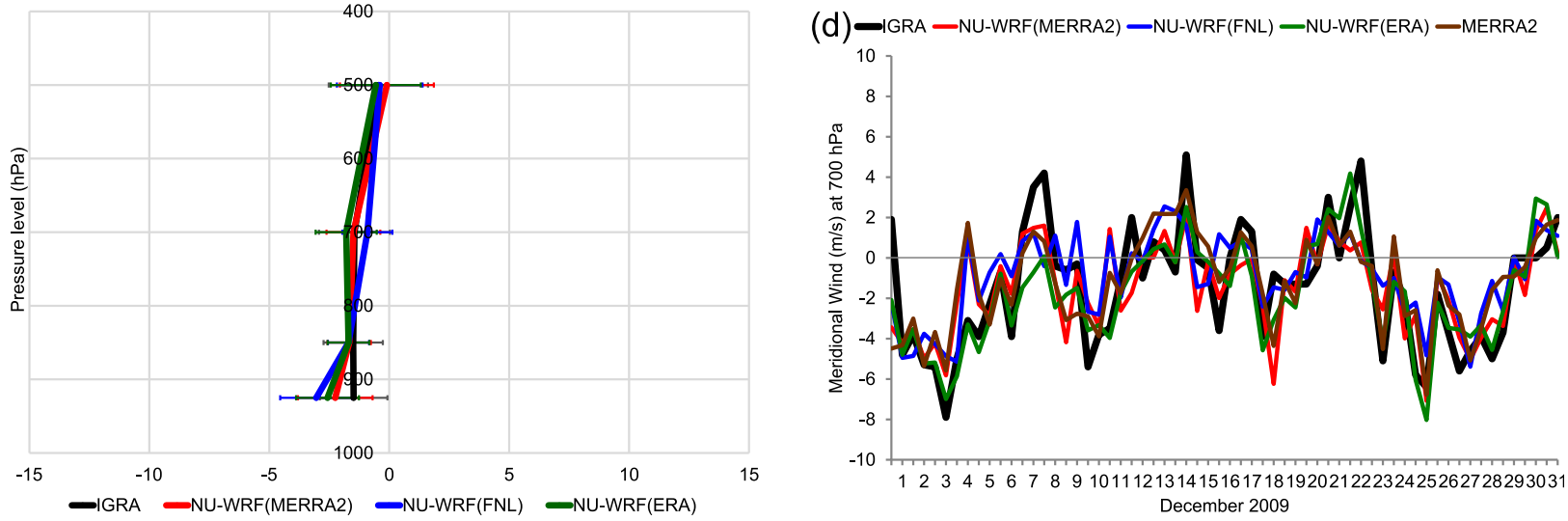

FIG. 11. As in Fig. 9, but at Niamey during December 2009.

The following discussion is developed on the assumption that the Banizoumbou AERONET site and the Niamey IGRA site are sufficiently close to each other, so that there is correlation between the physical quantities of the atmosphere over the two locations. The comparison between the observed monthly cycles of the meridional wind at $700 \mathrm{hPa}$ in Fig. 11d and AOD/AE in Fig. 10 suggests that the observed meridional wind at that pressure level is positively correlated with the observed AOD, particularly at the 440- and 400-nm wavelengths, and AE. For example, stronger southerly wind and higher AE were collocated on 7, 14, and 22 December. During those days, smaller aerosol particles related to biomass burning were advected from the south where such particles were dominant (Fig. 2b). In Figs. $10 \mathrm{~d}$ and $11 \mathrm{~d}$, the simulation results show substantial agreement between the $\mathrm{AE}$ and the meridional wind also, except for 22 December.

The increase in the simulated AOD due to biomassburning aerosols, which is coincident with high $\mathrm{AE}$ on 14 December, is demonstrated in the plots of the horizontal distributions of AOD and the wind fields at the 700-hPa level in Fig. 12. An anticyclonic circulation is simulated around $13^{\circ} \mathrm{N}, 12^{\circ} \mathrm{E}$, and a high AOD distribution extends northward on the western side of the circulation. The Banizoumbou and Niamey IGRA stations are covered with this relatively high AOD. This transport process of biomass-burning aerosols is similar to those in the cases of 12 and 16 April in Fig. 8, in which high AOD and AE values are simultaneously simulated at Dakar. The development of a local anticyclonic (i.e., high pressure) circulation along the AEJ plays a major role in the northward advection of biomass-burning aerosols to the Sahel from sub-Saharan western Africa. The relationship between the simulated wind and aerosol optical properties is consistent with that in the ground-site observation results in each month.

The importance of the wind at the 700-hPa level on the advection of biomass-burning aerosols to the north beyond $10^{\circ} \mathrm{N}$ may be explained using CALIPSO observations for the vertical aerosol distributions. Figure 13 shows vertical cross sections of 532-nm total attenuated 
(a) NU-WRF MERRA-2 AOD 12UTC 14 Dec

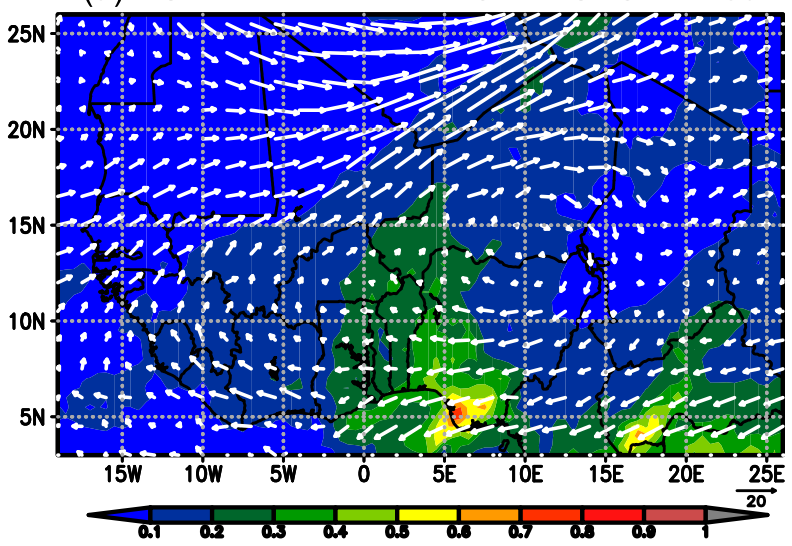

(b) NU-WRF FNL AOD 12UTC $14 \mathrm{Dec}$

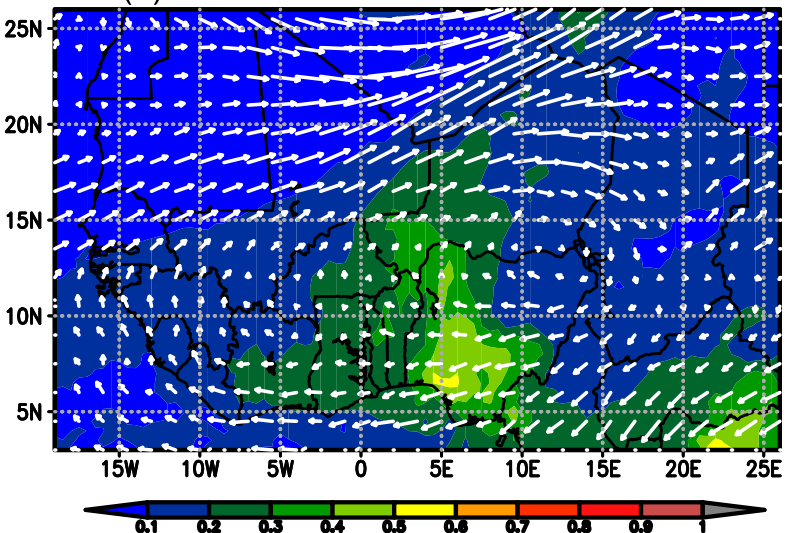

(c) NU-WRF Interim AOD 12UTC 14 Dec

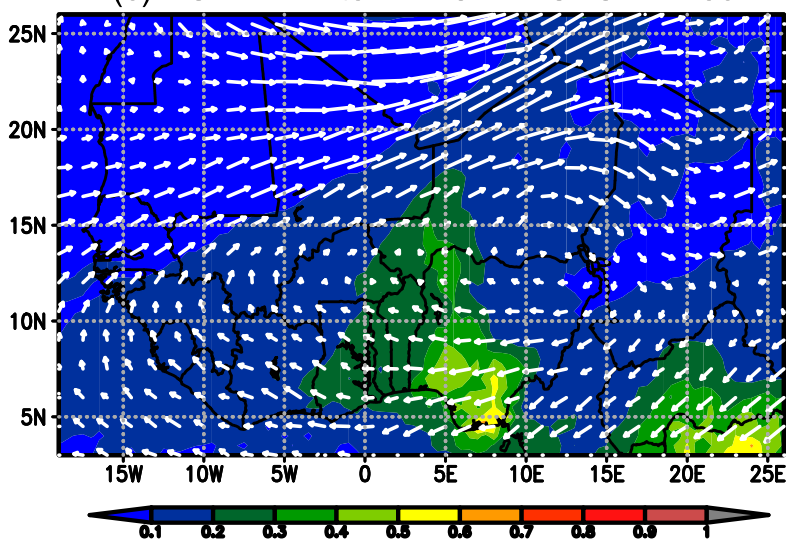

FIG. 12. As in Fig. 8, but at 1200 UTC 14 December 2009.

backscatter and aerosol subtype classification around 0200 UTC 7 December 2009 in the CALIPSO version-4.10 retrieval products. The satellite footprint passed in the vicinity of the Banizoumbou AERONET site and the Niamey IGRA site, so that the observed vertical structures could be similar to those over the two sites.
The observed vertical profiles from $11.5^{\circ}$ to $13.5^{\circ} \mathrm{N}$ exhibit a two-layer aerosol structure characterized by a mineral dust aerosol layer from approximately 1- to 2-km height above mean sea level (MSL) and clean continental and elevated smoke aerosol layers from 3- to 4-km height. The elevated smoke and clean continental aerosol layers seemed to spread out from the south to the north. Potential effects of the elevated aerosol layer are consistent with the results obtained from the Banizoumbou and Niamey sites on 7 December. Given that a pressure level of $700 \mathrm{hPa}$ corresponds approximately to $3.15-\mathrm{km}$ height MSL, the transport of smoke aerosols by southerly winds at that vertical level (Fig. 11d) seems to have caused large AE (Fig. 10d) on that day. These findings are generally consistent with those of Yang et al. (2013), who discussed vertical profiles of particulate matter through comparisons with CALIOP measurements.

\section{b. One-day simulations with 1-km grid spacing for specific biomass-burning cases}

Figure 14 shows the distribution of daily FRPs from the TerralAqua MODIS Collection 5 Active Fire Product for 16 April and 14 December 2009. Simulations were conducted for these dates using 1-day hindcasts from 0600 UTC. Relatively strong FRP spots were concentrated near the coastal area on 16 April, whereas relatively weak FRPs were widely distributed in the domain on 14 December.

Figure 15 illustrates the horizontal distributions of simulated AOD at a visible band (400-700-nm wavelength) over the simulation domains with $1-\mathrm{km}$ grid spacing at 2100 UTC 16 April and 14 December 2009, with a 700-hPa-level horizontal wind velocity overlay. The simulations for these plots employed a fixed injection height set as $650 \mathrm{~m}$ AGL, similar to the 1-month simulations with 9-km grid spacing. Higher AODs in the plots are caused mostly by aerosols emitted from biomass burning, because areas with higher AODs are distributed from higher FRP locations in Fig. 14. Overall, the aerosols are transported from biomass-burning areas according to wind direction at the $700-\mathrm{hPa}$ pressure level.

The sensitivity of vertical transport of smoke aerosols to the selection of the smoke injection parameterization is discussed below. Table 1 lists the designs of the sensitivity tests for each April and December case. The following three options for the modeled fixed smoke injection heights were tested to check the impacts on emitted aerosol transport: (i) the model bottom-layer top height in each WRF-model column (A1 and D1 in Table 1), (ii) $650 \mathrm{~m}$ AGL (A2 and D2), and (iii) $2000 \mathrm{~m}$ AGL (A3 and D3). The effects of the new parameterization described in the appendix were investigated with 
(a) CALIPSO-observed $532 \mathrm{~nm}$ ATB $\left[\mathrm{km}^{-1} \mathrm{str}^{-1}\right]$

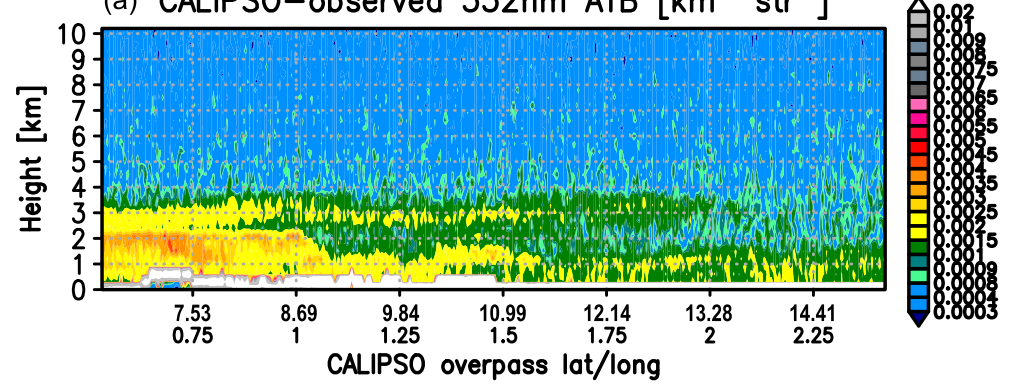

(b) CALIPSO Aerosol Subtype

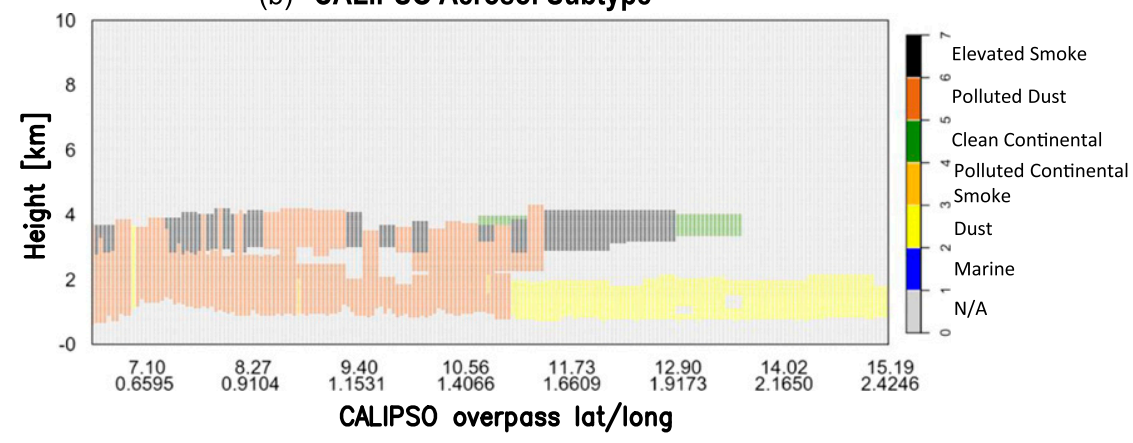

FIG. 13. Vertical cross sections of (a) 532-nm total (parallel + perpendicular) attenuated backscatter $\left(\mathrm{km}^{-1} \mathrm{sr}^{-1}\right)$ and (b) aerosol subtype classification retrieved from the lidar measurements by the CALIPSO core satellite along a track passing near Niamey around 0145 UTC 7 Dec 2009.

different magnifications $(\times 1, \times 10, \times 50$, and $\times 100)$ for the heat and vapor flux strengths released by the biomass burning (from A4 and D4 to A7 and D7).

Figure 16 shows time series of three height parameters indexing the vertical distribution of carbonaceous aerosol mass concentration averaged over the simulation domains; a height at which mass concentration accumulated from the bottom reaches $95 \%$ of the total in the vertical column (so-called 95th percentile) is used as an index for the top of the aerosol layer.

The comparison between A1/D1 and A2/D2 (the abbreviations are listed in Table 1) in Fig. 16 suggests that prescribing the smoke injection heights to the top of the bottom layer or to $650 \mathrm{~m}$ has little effect on the aerosol vertical distribution. Regardless of the injection height selection, the mean and maximum-value heights range roughly from 1.5 to $2 \mathrm{~km}$ MSL in the April case and from 1 to $1.5 \mathrm{~km}$ MSL in the December case, after the peak time of the biomass-burning emission. The 95th percentile heights reach approximately $3 \mathrm{~km}$ MSL after the peak time in both cases. The effect of the different injection heights is offset through upward advection and diffusion within convective planetary boundary layers (PBLs) during the daytime. However, the A3/D3 results show earlier increases in the three types of height parameters relative to those of $\mathrm{A} 1 / \mathrm{D} 1$ and $\mathrm{A} 2 / \mathrm{D} 2$ and maintain a slight increase until the end of the simulations. The effects of the 2000-m smoke injection height are slightly beyond the daytime convective PBL effects.

The simulations of A4/D4, A5/D5, A6/D6, and A7/D7 employed the new parameterization described in the appendix. The results of A4/D4 are almost consistent with those of A1/D1 and A2/D2, implying that the new parameterization for heat release by biomass burning has little effect on the aerosol profile when the flux strengths are not amplified. However, A5/D5, A6/D6, and A7/D7 show increased height parameters according to the relative magnification factors applied to the flux strengths. The parameterized amplified latent and sensible heat fluxes change the atmospheric structure near the surface in these simulations, so that emitted aerosols are transported to higher levels. The effects are similar to those for the 2000-m fixed injection height in A3/D3, except that the increases in the height parameters are delayed in A5/D5, A6/D6, and A7/D7 relative to A3/D3. Unlike the experiments using fixed smoke injection heights, the timing of the height increase is closer to the diurnal peak time of the biomass-burning emission in A5/D5, A6/D6, and A7/D7, because the parameterized effects are dependent on the FRP magnitude with the diurnal cycle. These results demonstrate that the new parameterization could provide flexibility on 

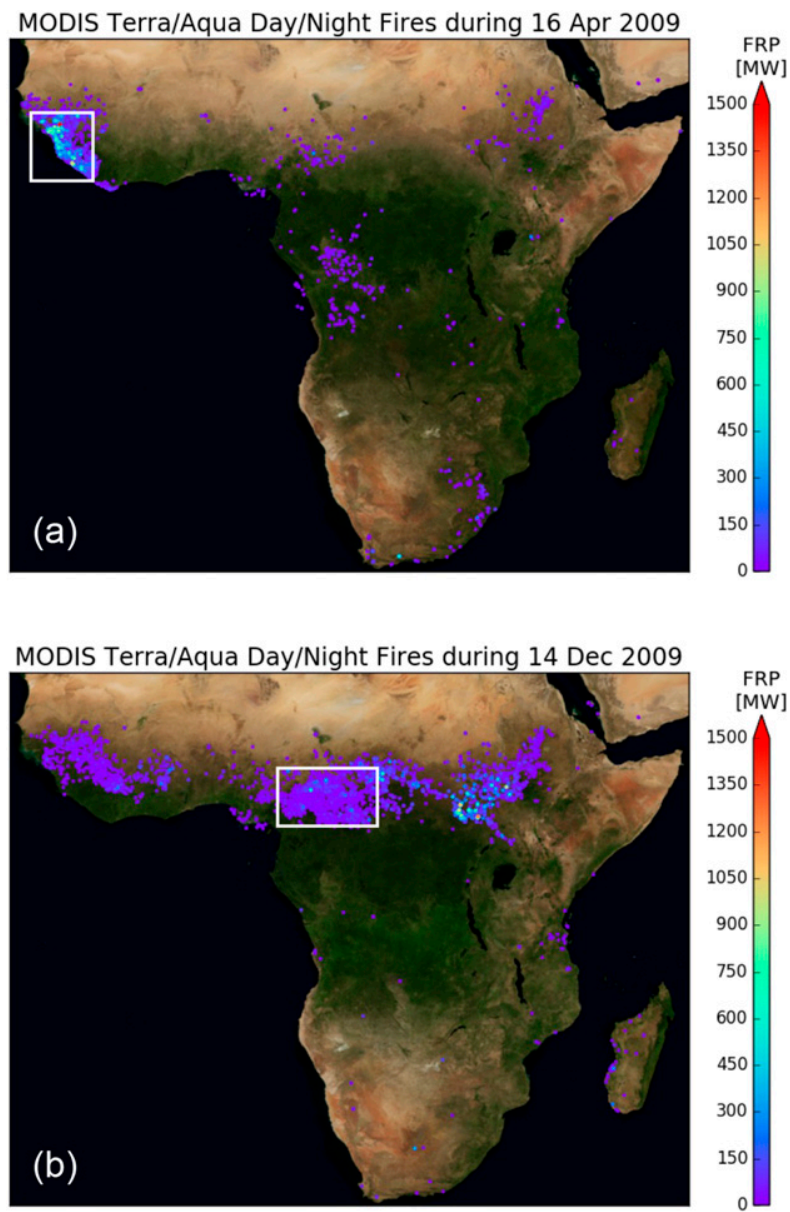

FIG. 14. Daily FRP (MW) distribution derived from the Terral Aqua MODIS Collection 5 Active Fire Product on (a) 16 Apr and (b) 14 Dec 2009. The areas enclosed by the white squares show the simulation subdomains with horizontal grid spacing of $1 \mathrm{~km}$.

changing aerosol vertical profiles according to the strength of satellite-observed biomass burning rather than using the artificial injection height assumptions. In addition, the larger 95th-percentile heights in A6 and A7 when compared with respectively those of D6 and D7 may be caused by the higher FRP in the April case than in the December case (Fig. 14).

Figure 17 illustrates the vertical distribution of domainaveraged carbonaceous aerosol concentrations at 2100 UTC in the April and December cases. The April case shows roughly unimodal distributions, whereas the simulations in the December case show clear bimodal distributions. Some parts of carbonaceous aerosols seem to be trapped in nighttime stable PBLs close to the surface in the December case.

The results in Figs. 16 and 17 suggest that the peak and top heights of simulated biomass-burning aerosols are located roughly between 1.5 and $3 \mathrm{~km}$ MSL (i.e., approximately $850-$ and $700-\mathrm{hPa}$ pressure levels). This (a) AOD with 700-hPa wind overlay 21UTC 16 April 2009

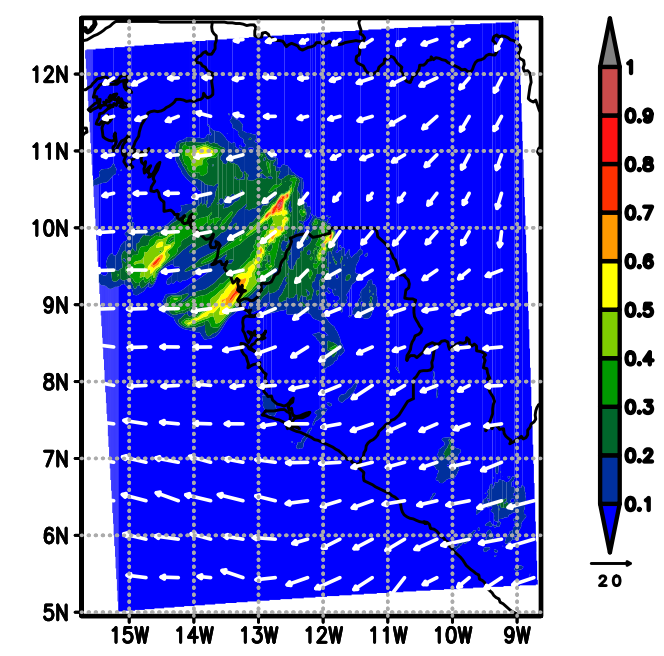

(b) AOD with 700-hPa wind overlay 21UTC 14 December 2009

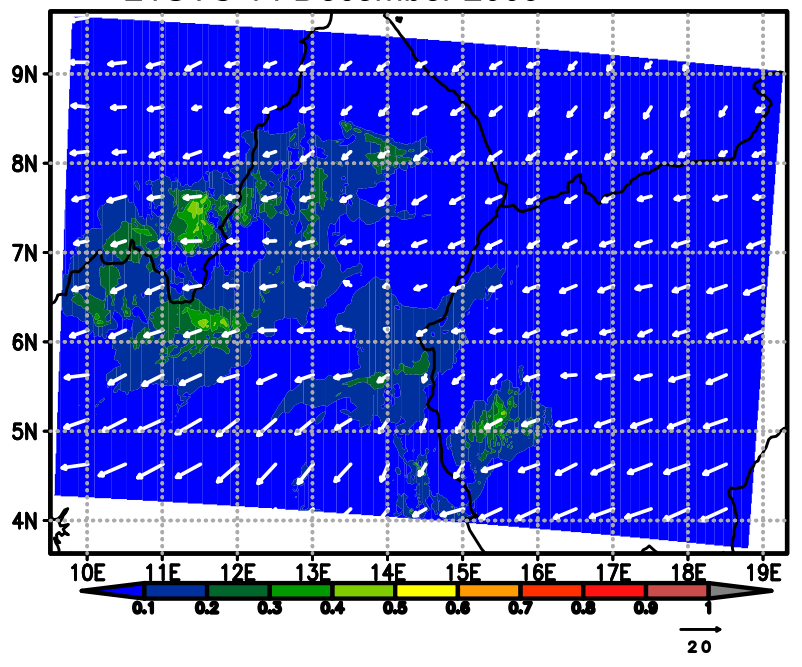

FIG. 15. Distribution of AOD at a visible band (400-700-nm wavelength) with 700 -hPa horizontal wind vectors overlaid at 2100 UTC (a) 16 Apr 2009 and (b) 14 Dec 2009, simulated by the NU-WRF 1-km simulations.

finding supports the agreement between horizontal wind at $700 \mathrm{hPa}$ and the horizontal transport of biomassburning aerosols to the Dakar and Niamey/Banizoumbou sites, which are discussed in section 3a. However, the wind at $850 \mathrm{hPa}$ was less consistent with AOD and $\mathrm{AE}$ at those sites than the wind at $700 \mathrm{hPa}$. The reason is probably because the 850 -hPa level is closer to or within the PBL, so that the wind at this level has a greater temporal and spatial variability. As a result, the wind at $700 \mathrm{hPa}$ works better as an index to show the large-scale horizontal transport of aerosols between 
TABLE 1. Design of sensitivity tests in the NU-WRF simulations with 1-km horizontal grid spacing. Letters $\mathrm{A}$ and $\mathrm{D}$ denote the simulations for 16-17 Apr and 14-15 Dec 2009, respectively.

\begin{tabular}{|c|c|c|}
\hline Abbreviation & $\begin{array}{c}\text { Smoke injection } \\
\text { height }\end{array}$ & $\begin{array}{l}\text { Magnification for flux } \\
\text { strength }^{\mathrm{a}}\end{array}$ \\
\hline A1, D1 & $\begin{array}{l}\text { Top of model } \\
\text { bottom layer }^{\mathrm{b}}\end{array}$ & $-^{c}$ \\
\hline $\mathrm{A} 2, \mathrm{D} 2$ & $650 \mathrm{~m}$ & - \\
\hline A3, D3 & $2000 \mathrm{~m}$ & - \\
\hline $\mathrm{A} 4, \mathrm{D} 4$ & $\begin{array}{l}\text { Top of model } \\
\text { bottom layer }\end{array}$ & $\times 1$ \\
\hline A5, D5 & $\begin{array}{l}\text { Top of model } \\
\text { bottom layer }\end{array}$ & $\times 10$ \\
\hline A6, D6 & $\begin{array}{l}\text { Top of model } \\
\text { bottom layer }\end{array}$ & $\times 50$ \\
\hline A7, D7 & $\begin{array}{l}\text { Top of model } \\
\text { bottom layer }\end{array}$ & $\times 100$ \\
\hline
\end{tabular}

${ }^{a}$ Magnifications to perturb the sensible and latent heat fluxes of Eqs. (A3) and (A4) in the appendix.

${ }^{b}$ The top height of the model bottom atmospheric layer is set as the smoke injection height.

${ }^{c}$ The parameterization described in the appendix is not applied.

1.5 and $3 \mathrm{~km}$ MSL. Since 700 and $850 \mathrm{hPa}$ correspond approximately with 3 and $1.5 \mathrm{~km}$ MSL, respectively, it might be appropriate to conduct further studies to explore the validity of a generalization that the transport of an aerosol layer is best characterized using the wind parameters of the pressure level closest to the top of the layer.

\section{Summary and conclusions}

A series of hindcast simulations were conducted to evaluate the performance of the NU-WRF WRF-Chem model as a simulation tool of biomass-burning aerosol transport over West Africa. Two types of nested domains were configured to explore the large-scale horizontal transport and the vertical transport near the burning areas, separately. First, 1-month simulations were conducted for April and December 2009 with 9-km horizontal grid spacing, to investigate the model reproducibility skill against satellite- and ground-based measurements. Second, 1-day simulations with 1-km horizontal grid spacing were conducted to focus on the variability of vertical transport of aerosols according to different parameterizations of the smoke lifting and injection rates.

The comparison between the measurements and the simulations with $9-\mathrm{km}$ grid spacing showed that wind components at $700 \mathrm{hPa}$ worked as an index to explain the northward transport of the biomass-burning aerosols beyond $10^{\circ} \mathrm{N}$ from the south, where biomass burning was active. The simulations demonstrated how the development of clockwise (i.e., high pressure) circulation along an AEJ caused the substantial northward transport of the biomassburning aerosols. Such close relationships between the vertical accumulation of the biomass-burning aerosols and their horizontal transport around $700 \mathrm{hPa}$ were previously discussed by Yang et al. (2013) through the comparison of simulations with CALIOP observations. The present study further justified their conclusions through the comparison of horizontal wind components with the sounding data in the Sahel region.

The model simulations with 9-km grid spacing generally underpredicted satellite-observed monthly AODs, especially over the eastern Sahara, and AE, especially over sub-Saharan West Africa south of $10^{\circ} \mathrm{N}$ in both months. The comparison with AOD and AE from AERONET ground-site observations showed that the model also underpredicted AOD, particularly when its increase was coincident with low AE. However, the model did not under- or overpredict AERONET AE roughly on the monthly average. Since the comparison of the aerosol optical parameters with AERONET observations was conducted in a more consistent manner (similar wavelengths) than that with the satellite measurements, the underprediction of AOD, particularly due to dust particles, is certain but the bias in AE could be due to uncertainties in the satellite retrievals. At times when AE is larger and AOD is still underpredicted, smoke emissions can also be underpredicted because of the lack of sensitivity of MODIS to detecting fires at the edges of satellite swaths and no observations of fires in the gaps between each MODIS ground track in equatorial and subequatorial regions (Wang et al. 2018).

A new simple parameterization for the effects of heat release by biomass burning based on the satellitemeasured FRP data was designed for kilometer- or subkilometer-scale simulations. This parameterization was tested in nested domains with $1-\mathrm{km}$ grid spacing. The simulation results showed that vertical profiles of biomass-burning aerosols were slightly sensitive to the selection of the parameterizations used in this study, except for cases assuming extreme heat release from biomass burning. Emitted aerosols were transported upward and mixed within the daytime convective PBL, even if the aerosols were injected only into the model's bottom layer. The peak and top heights of simulated biomass-burning aerosols were located roughly between 1.5 and $3 \mathrm{~km}$ MSL. These results were consistent with the findings that wind at the $700-\mathrm{hPa}$ pressure level was a key factor in the horizontal transport of biomass-burning aerosols on the subcontinental scale.

The vertical transport of biomass-burning aerosols could vary with the observed FRP magnitude (i.e., the density and strength of the biomass burning), as introduced 
(a) $-\mathrm{A} 1-\mathrm{A} 2-\mathrm{A} 3--\mathrm{A} 4--\mathrm{A} 5--\mathrm{A} 6--\mathrm{A} 7$

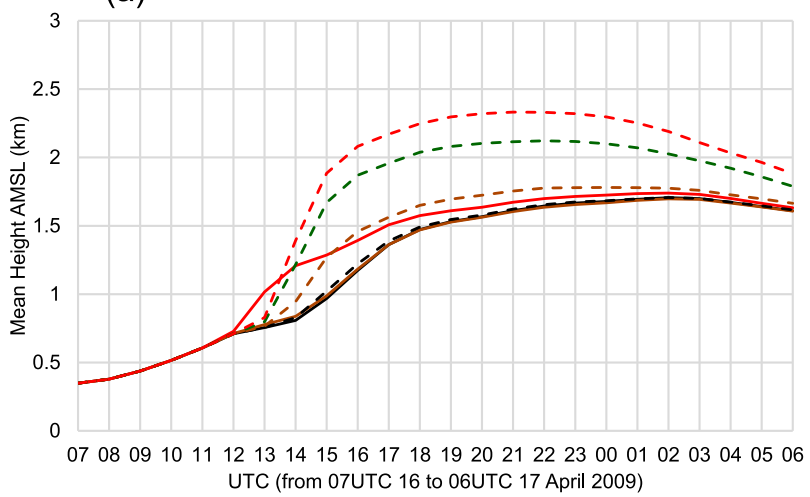

(b) $-\mathrm{A} 1-\mathrm{A} 2-\mathrm{A} 3--\mathrm{A} 4--\mathrm{A} 5--\mathrm{A} 6--\mathrm{A} 7$

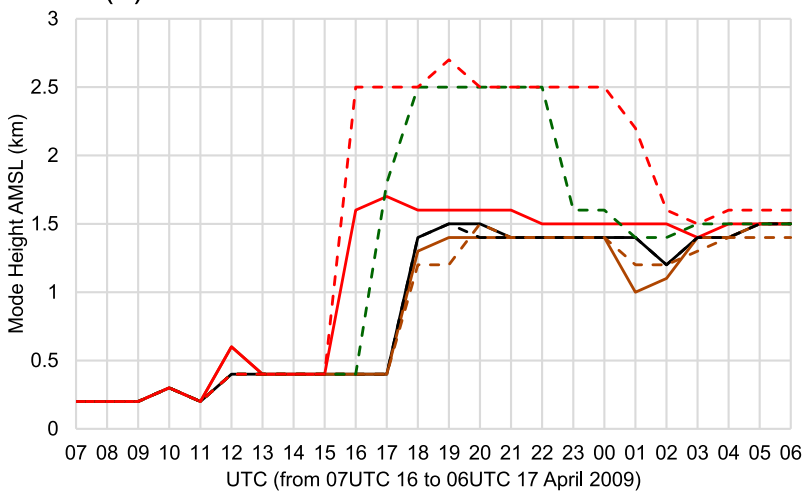

(c) $-\mathrm{A} 1-\mathrm{A} 2-\mathrm{A} 3--\mathrm{A} 4--\mathrm{A} 5--\mathrm{A} 6--\mathrm{A} 7$

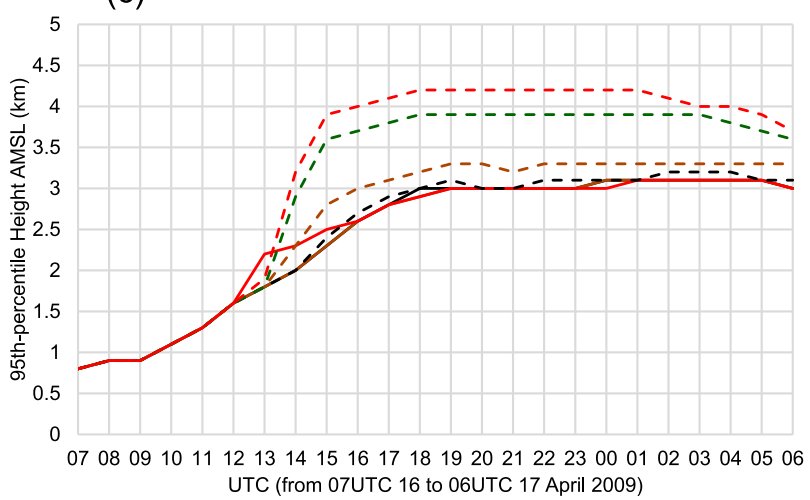

(d) $-D 1-D 2-D 3--D 4--D 5--D 6--D 7$

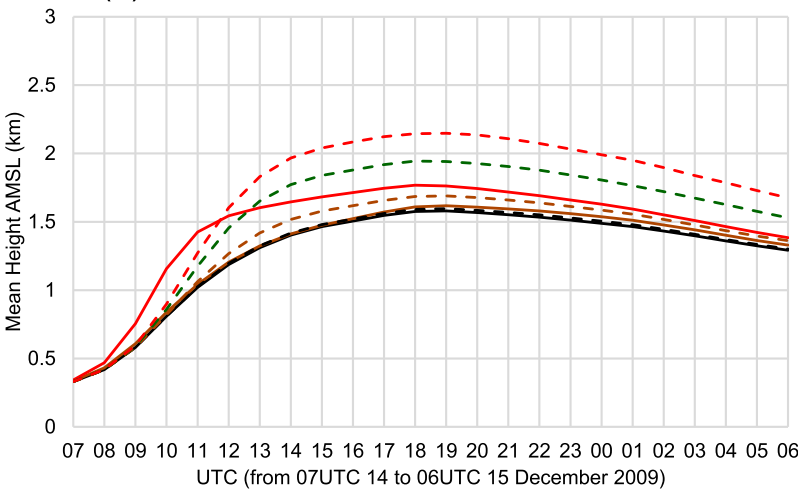

(e) -D1 - D2 -D3 - -D4 - -D5 - -D6 - -D7

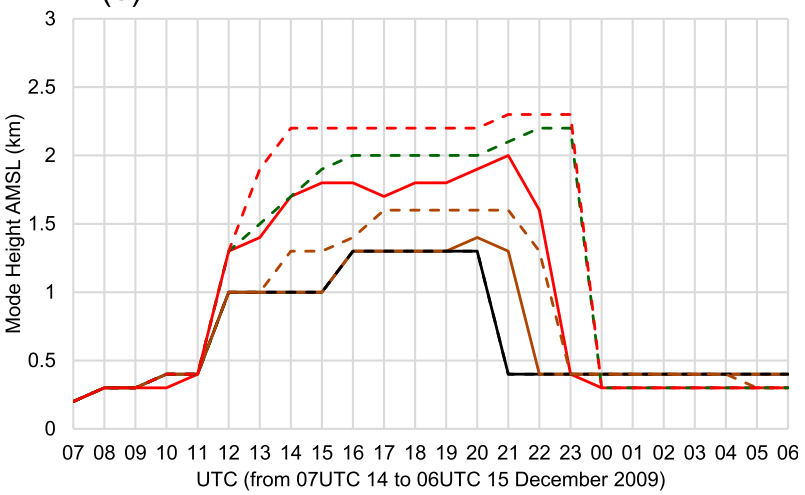

(f) $-\mathrm{D} 1-\mathrm{D} 2-\mathrm{D} 3--\mathrm{D} 4--\mathrm{D} 5--\mathrm{D} 6--\mathrm{D} 7$

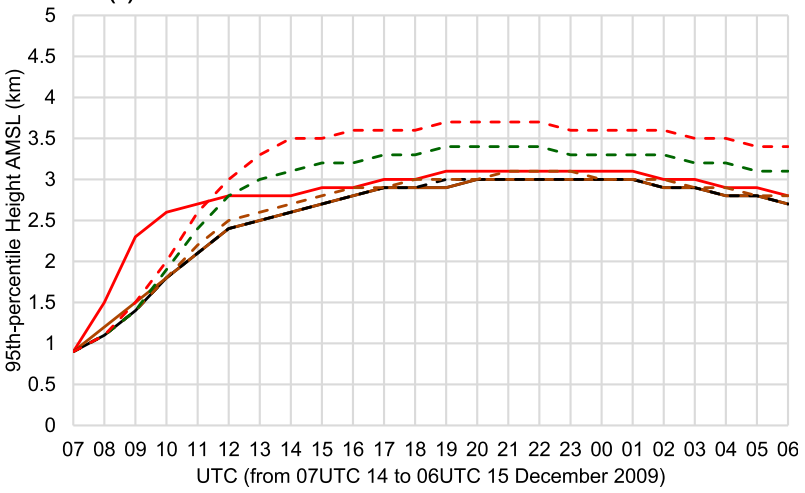

FIG. 16. Time series of (a),(d) mean height MSL, (b),(e) height MSL with the maximum value, and (c),(f) 95th-percentile height MSL of simulated carbonaceous aerosol mass concentrations averaged over the domain of the NU-WRF model 1-km simulations (left) from 0600 UTC 16 Apr to 0600 UTC 17 Apr 2009, and (right) from 0600 UTC 14 Dec to 0600 UTC 15 Dec 2009. The abbreviations in the plot legends are identical to those in Table 1.

through the model parameterization. The parameterization could work reasonably well and offer better flexibility relative to conventional parameterizations based on the fixed smoke injection heights. Since the new parameterization has been developed for cloud-resolving scales $(\sim 1 \mathrm{~km})$, it has the potential to better simulate the interaction between biomass burning and convective systems/clouds in future studies. However, the performance of the parameterization could not be evaluated in this study, because of the absence of coincident corresponding in situ or airborne measurements for satellitebased FRPs and fire areas (e.g., Peterson et al. 2013), elevated smoke properties, and the carbonaceous aerosol distribution from active biomass burning. The features of such smoke from biomass burning over West Africa are usually hidden in CALIPSO measurements, as a result of its mixture with dust aerosol particles transported from the Sahara, as shown in Fig. 13 and also Yang et al. (2013). 
(a) 21 UTC 16 April 2009

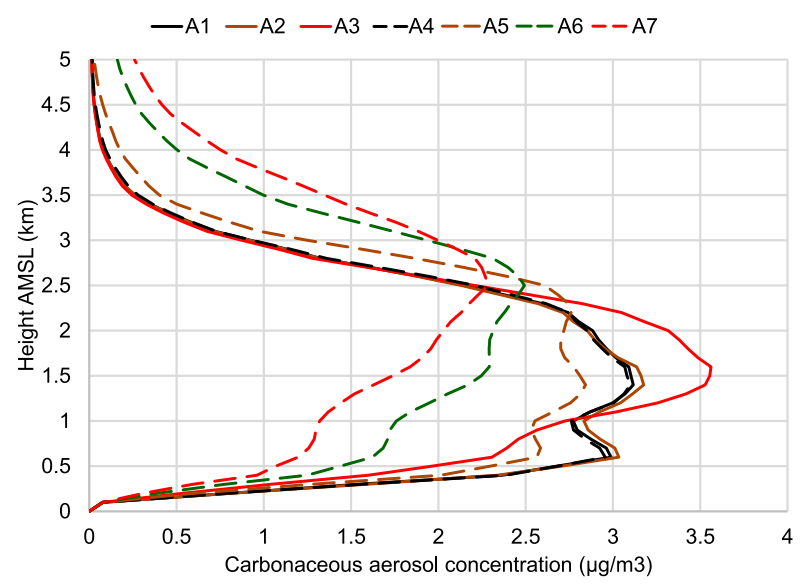

(b) 21 UTC 14 December 2009

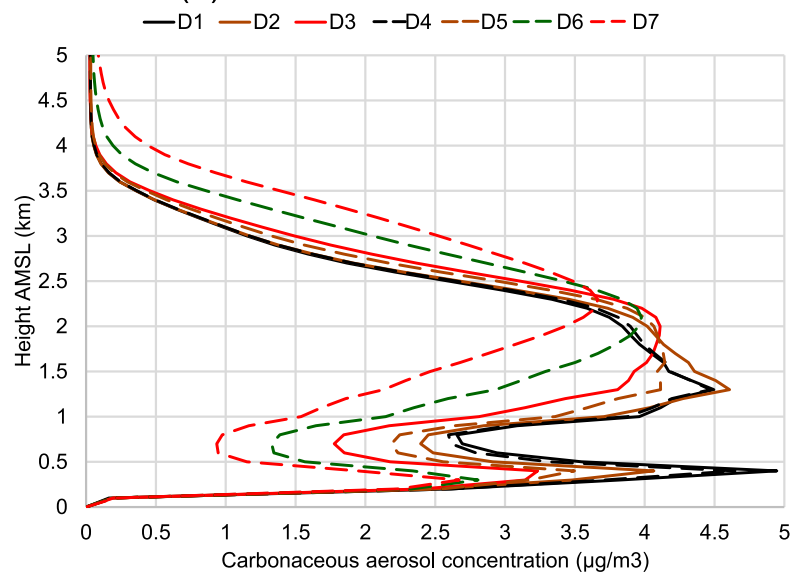

FIG. 17. Vertical profiles of simulated carbonaceous aerosol mass concentrations averaged over the domain of the NU-WRF model 1-km simulations at 2100 UTC (a) 16 Apr and (b) 14 Dec 2009. The abbreviations in the plot legends are identical to those in Table 1.

Quantitative evaluation of such simulation results would require field measurement campaigns with aircraft as well as further advanced use of geostationary satellite observations (e.g., Solomos et al. 2015) to trace biomass-burning smoke aerosols under different environmental conditions.

Acknowledgments. This study was funded under the NASA Research Opportunities in Space and Earth Sciences (ROSES)-2009 and 2013 Interdisciplinary Studies (IDS) Program (Dr. Jack Kaye, Earth Science Research Director) through the Radiation Sciences Program (Dr. Hal Maring, Program Manager) in support of the project entitled: "Interactions and Feedbacks between Biomass Burning and Water Cycle Dynamics across the Northern Sub-Saharan African Region" (Project PI: Charles Ichoku). The MERRA-2 data were provided by the NASA Global Modeling and
Assimilation Office (GMAO). Lauren Zamora of NASA GSFC and the University of Maryland helped to make the plots of the CALIPSO retrieval products (Fig. 10). We thank Didier Tanré of Lab. d'Optique Atmosphérique and U.S.T. de Lille and Jean Louis Rajot of Laboratoire Interuniversitaire des Systèmes Atmosphériques for their efforts in establishing and maintaining the Banizoumbou and Dakar AERONET sites. We also acknowledge the providers of the sounding data of IGRA V2 and the SeaWiFS, MODIS, MISR, and CALIPSO satellite products. The authors thank the four anonymous reviewers and the journal editors for their helpful comments in improving this paper.

\section{APPENDIX}

\section{Parameterization of the Effects of Heat Release by Biomass Burning on Smoke Spread}

A new parameterization has been designed and developed to represent the heat and vapor release from surface wildfires. The approach includes the released heat and vapor fluxes and follows the method in the WRF dynamics core coupled with the fire-spread model (WRF-SFIRE; e.g., Mandel et al. 2011; Coen et al. 2013). The flux divergences are included as additional tendencies of the potential temperature and vapor calculation into multiple layers on the basis of an assumed extinction depth of surface fire heat. However, unlike WRF-SFIRE, our parameterization does not calculate the detailed processes and properties of wildfires. Alternatively, the strengths of the heat and vapor fluxes are constrained by the FRP derived from the MODIS fire algorithm products, which was also used to create the FEER emission products.

The release rate of the total radiative energy $E_{f}$ emitted from wildfires within a pixel is estimated using the 4- $\mu \mathrm{m}$ channel radiance in the fire retrieval algorithm of the MODIS Collection 6 product [e.g., Giglio et al. (2016), Eq. (16)]:

$$
E_{f} \approx \frac{A_{\mathrm{pix}} \sigma}{a \tau_{4}}\left(L_{4}-L_{4 b}\right),
$$

where $L_{4}$ and $L_{4 b}$ are the $4-\mu \mathrm{m}$ radiance of the target pixel and surrounding nonburned background pixels, respectively; $A_{\text {pix }}$ is the area of the pixel; $\sigma$ is the StefanBoltzmann constant; $\tau_{4}$ is the atmospheric transmittance for the 4- $\mu \mathrm{m}$ channel; and $a$ is a sensor-specific empirical constant.

Here, $E_{f}$ is correlated to the mass combustion rate of biomass $M_{\mathrm{bm}}$, and the relationship between these two 
variables is approximated by the following equation [Wooster et al. (2005), their Eq. (14)]:

$$
d M_{\mathrm{bm}} / d t=0.368 \times 10^{-6} E_{f} \quad\left(\mathrm{~kg} \mathrm{~m}^{-2} \mathrm{~s}^{-1}\right),
$$

where $d M_{\mathrm{bm}} / d t$ is assumed to be the rate of combustion of the fuel mass, which releases sensible and latent heat fluxes to the atmosphere. The magnitude of the sensible heat flux $H_{s}$ is calculated using the following equation [Coen et al. (2013), their Eq. (7)]:

$$
H_{s}=d M_{\mathrm{bm}} / d t(1-B) h_{c} \quad\left(\mathrm{~W} \mathrm{~m}^{-2}\right),
$$

where $B$ is the mass fraction of water in the fuel and $h_{c}\left(\mathrm{~J} \mathrm{~kg}^{-1}\right)$ is the heat release rate of the fuel mass through combustion; the values of 0.074 for $B$ and $17.433 \times 10^{6} \mathrm{~J} \mathrm{~kg}^{-1}$ for $h_{c}$ are cited from the WRFSFIRE model. The magnitude of the latent heat flux $L_{s}$ is calculated based on Coen et al. [2013, their Eq. (9)]:

$$
L_{s}=d M_{\mathrm{bm}} / d t[B+0.56(1-B)] l_{v} \quad\left(\mathrm{~W} \mathrm{~m}^{-2}\right)
$$

where $l_{v}$ is the latent heat release rate through water vaporization. The calculated sensible and latent heat fluxes are included in the calculation of the tendency updates of the potential temperature and vapor mixing ratio at each time step. The additional tendency terms are distributed in multiple atmospheric layers on the basis of an assumed extinction depth of the surface fire heat. The depth is assumed to be $50 \mathrm{~m}$ in this study, which is consistent with WRF-SFIRE (Mandel et al. 2011; Coen et al. 2013).

\section{REFERENCES}

Abel, S. J., E. J. Highwood, J. M. Haywood, and M. A. Stringer, 2005: The direct radiative effect of biomass burning aerosols over southern Africa. Atmos. Chem. Phys., 5, 1999-2018, https://doi.org/10.5194/acp-5-1999-2005.

Berry, G., C. Thorncroft, and T. Hewson, 2007: African easterly waves during 2004-Analysis using objective techniques. Mon. Wea. Rev., 135, 1251-1267, https://doi.org/ 10.1175/MWR3343.1.

Bosilovich, M. G., and Coauthors, 2015: MERRA-2: Initial evaluation of the climate. NASA Tech. Memo. NASA/TM-2015104606/Vol. 43, 145 pp., https:/gmao.gsfc.nasa.gov/pubs/docs/ Bosilovich803.

Buchard, V., and Coauthors, 2015: Using the OMI aerosol index and absorption aerosol optical depth to evaluate the NASA MERRA aerosol reanalysis. Atmos. Chem. Phys., 15, 57435760, https://doi.org/10.5194/acp-15-5743-2015.

CALIPSO Science Team, 2015: CALIPSO/CALIOP lidar aerosol profile data, version 4.10. NASA Atmospheric Science Data Center, accessed 13 May 2016, https:/doi.org/10.5067/caliop/ calipso/lid_12_05kmapro-standard-v4-10.

Cautenet, S., and Coauthors, 1999: Simulation of carbon monoxide redistribution over central Africa during biomass burning events (experiment for regional sources and sinks of oxidants (EXPRESSO)). J. Geophys. Res., 104, 30 641-30 657, https:// doi.org/10.1029/1999JD900393.

Chin, M., R. B. Rood, S.-J. Lin, J.-F. Müller, and A. M. Thompson, 2000a: Atmospheric sulfur cycle simulated in the global model GOCART: Model description and global properties. J. Geophys. Res., 105, 24671-24687, https://doi.org/10.1029/ 2000JD900384.

- and Coauthors, 2000b: Atmospheric sulfur cycle simulated in the global model GOCART: Comparison with field observations and regional budgets. J. Geophys. Res., 105, 24689 24712 , https://doi.org/10.1029/2000JD900385.

Chou, M.-D., and M. J. Suarez, 1999: A solar radiation parameterization for atmospheric studies. Tech. Memo. NASA/ TM-1999-104606, Vol. 15, 38 pp., http://gmao.gsfc.nasa.gov/ pubs/docs/Chou136.pdf.

,,-- X.-Z. Liang, and M. M.-H. Yan, 2001: A thermal infrared radiation parameterization for atmospheric studies. NASA/TM-2001-104606, Vol. 19, 54 pp., https://ntrs.nasa.gov/ archive/nasa/casi.ntrs.nasa.gov/20010072848.pdf.

Coen, J. L., M. Cameron, J. Michalakes, E. G. Patton, P. J. Riggan, and K. M. Yedinak, 2013: WRF-Fire: Coupled weatherwildland fire modeling with the Weather Research and Forecasting Model. J. Appl. Meteor. Climatol., 52, 16-38, https:// doi.org/10.1175/JAMC-D-12-023.1.

Colarco, P. R., M. R. Schoeberl, B. G. Doddridge, L. T. Marufu, O. Torres, and E. J. Welton, 2004: Transport of smoke from Canadian forest fires to the surface near Washington, D.C.: Injection height, entrainment, and optical properties. J. Geophys. Res., 109, D06203, https://doi.org/10.1029/ 2003JD004248.

Dee, D. P., and Coauthors, 2011: The ERA-Interim reanalysis: Configuration and performance of the data assimilation system. Quart. J. Roy. Meteor. Soc., 137, 553-597, https://doi.org/ 10.1002/qj.828.

Delmas, R. A., P. Loudjani, A. Podaire, and J.-C. Menaut, 1991: Biomass burning in Africa: An assessment of annually burned biomass. Global Biomass Burning: Atmospheric, Climatic, and Biospheric Implications, J. S. Levine, Ed., MIT Press, 126-132.

Durre, I., and X. Yin, 2008: Enhanced radiosonde data for studies of vertical structure [in "Nowcast"]. Bull. Amer. Meteor. Soc., 89 (9), 1257-1260.

Freitas, S. R., and Coauthors, 2007: Including the sub-grid scale plume rise of vegetation fires in low resolution atmospheric transport models. Atmos. Chem. Phys., 7, 3385-3398, https:// doi.org/10.5194/acp-7-3385-2007.

processor of trace gas and aerosol emission fields for regional and global atmospheric chemistry models. Geosci. Model Dev., 4, 419-433, https://doi.org/10.5194/gmd-4-419-2011.

Gatebe, C. K., C. Ichoku, R. Poudyal, M. O. Román, and E. Wilcox, 2014: Surface albedo darkening from wildfires in northern sub-Saharan Africa. Environ. Res. Lett., 9, 065003, https://doi.org/10.1088/1748-9326/9/6/065003.

Ge, C., J. Wang, J. S. Reid, D. Posselt, P. Xian, and E. Hyer, 2017: Mesoscale modeling of smoke transport from equatorial Southeast Asian Maritime Continent to the Philippines: First comparison of ensemble analysis with in situ observations. J. Geophys. Res. Atmos., 122, 5380-5398, https://doi.org/ 10.1002/2016JD026241.

Giglio, L., 2013: MODIS collection 5 active fire product user's guide, version 2.5. Dept. of Geography, University of Maryland, 
College Park, 61 pp., https://cdn.earthdata.nasa.gov/conduit/ upload/907/MODIS_Fire_Users_Guide_2.5.pdf.

—- W. Schroeder, and C. O. Justice, 2016: The collection 6 MODIS active fire detection algorithm and fire products. Remote Sens. Environ., 178, 31-41, https://doi.org/10.1016/ j.rse.2016.02.054

Ginoux, P., M. Chin, I. Tegen, J. M. Prospero, B. Holben, O. Dubovik, and S.-J. Lin, 2001: Sources and distributions of dust aerosols simulated with the GOCART model. J. Geophys. Res., 106, 20 255-20 273, https://doi.org/10.1029/ 2000JD000053.

Grell, G. A., and D. Dévényi, 2002: A generalized approach to parameterizing convection combining ensemble and data assimilation techniques. Geophys. Res. Lett., 29, 1693, https:// doi.org/10.1029/2002GL015311.

Guenther, A., T. Karl, P. Harley, C. Wiedinmyer, P. I. Palmer, and C. Geron, 2006: Estimates of global terrestrial isoprene emissions using MEGAN (Model of Emissions of Gases and Aerosols from Nature). Atmos. Chem. Phys., 6, 3181-3210, https://doi.org/10.5194/acp-6-3181-2006.

Holben, B., and Coauthors, 1998: AERONET-A federated instrument network and data archive for aerosol characterization. Remote Sens. Environ., 66, 1-16, https://doi.org/10.1016/ S0034-4257(98)00031-5.

Hsu, N. C., R. Gautam, A. M. Sayer, C. Bettenhausen, C. Li, M. J. Jeong, S.-C. Tsay, and B. Holben, 2012: Global and regional trends of aerosol optical depth over land and ocean using SeaWiFS measurements from 1997 to 2010. Atmos. Chem. Phys., 12, 8037-8053, https://doi.org/10.5194/acp-12-8037-2012.

, A. M. Sayer, M.-J. Jeong, and C. Bettenhausen, 2013: SeaWiFS deep blue aerosol optical depth and angstrom exponent monthly level 3 data gridded at 0.5 degrees V004. Goddard Earth Sciences Data and Information Services Center, accessed 7 July 2017, https://doi.org/10.5067/MEASURES/ SWDB/DATA303.

Ichoku, C., and Y. J. Kaufman, 2005: A method to derive smoke emission rates from MODIS fire radiative energy measurements. IEEE Trans. Geosci. Remote Sens., 43, 2636-2649, https://doi.org/10.1109/TGRS.2005.857328.

_ sions estimation using satellite fire radiative power measurements. Atmos. Chem. Phys., 14, 6643-6667, https://doi.org/ 10.5194/acp-14-6643-2014.

— L. Liglio, M. J. Wooster, and L. A. Remer, 2008: Global characterization of biomass-burning patterns using satellite measurements of fire radiative energy. Remote Sens. Environ., 112, 2950-2962, https://doi.org/10.1016/j.rse.2008.02.009.

, and Coauthors, 2016: Biomass burning, land-cover change, and the hydrological cycle in northern subSaharan Africa. Environ. Res. Lett., 11, 095005, https:// doi.org/10.1088/1748-9326/11/9/095005.

Johnson, B. T., B. Heese, S. A. McFarlane, P. Chazette, A. Jones, and N. Bellouin, 2008: Vertical distribution and radiative effects of mineral dust and biomass burning aerosol over West Africa during DABEX. J. Geophys. Res., 113, D00C12, https://doi.org/10.1029/2008JD009848.

Kim, D., M. Chin, E. M. Kemp, Z. Tao, C. D. Peters-Lidard, and P. Ginoux, 2017: Development of high-resolution dynamic dust source function-A case study with a strong dust storm in a regional model. Atmos. Environ., 159, 11-25, https:// doi.org/10.1016/j.atmosenv.2017.03.045.

Lamarque, J. F., and Coauthors, 2013: The Atmospheric Chemistry and Climate Model Intercomparison Project (ACCMIP):
Overview and description of models, simulations and climate diagnostics. Geosci. Model Dev., 6, 179-206, https://doi.org/ 10.5194/gmd-6-179-2013.

Lang, S., W.-K. Tao, J. Simpson, R. Cifelli, S. Rutledge, W. Olson, and J. Halverson, 2007: Improving simulations of convective systems from TRMM LBA: Easterly and westerly regimes. J. Atmos. Sci., 64, 1141-1164, https://doi.org/ 10.1175/JAS3879.1.

Lau, K. M. W., K.-M. Kim, J.-J. Shi, T. Matsui, M. Chin, Q. Tan, C. Peters-Lidard, and W. K. Tao, 2017: Impacts of aerosol-monsoon interaction on rainfall and circulation over northern India and the Himalayan foothills. Climate Dyn., 49, 1945-1960, https://doi.org/ 10.1007/s00382-016-3430-y.

Levy, R., and Coauthors, 2015: MODIS atmosphere L2 aerosol product. NASA MODIS Adaptive Processing System, Goddard Space Flight Center, accessed 1 March 2018, https:// doi.org/10.5067/MODIS/MOD04_L2.006.

Liousse, C., and Coauthors, 2010: Updated African biomass burning emission inventories in the framework of the AMMAIDAF program, with an evaluation of combustion aerosols. Atmos. Chem. Phys., 10, 9631-9646, https://doi.org/10.5194/ acp-10-9631-2010.

Luderer, G., J. Trentmann, T. Winterrath, C. Textor, M. Herzog, H. F. Graf, and M. O. Andreae, 2006: Modeling of biomass smoke injection into the lower stratosphere by a large forest fire (Part II): Sensitivity studies. Atmos. Chem. Phys., 6, 52615277, https://doi.org/10.5194/acp-6-5261-2006.

Mandel, J., J. D. Beezley, and A. K. Kochanski, 2011: Coupled atmosphere-wildland fire modeling with WRF 3.3 and SFIRE 2011. Geosci. Model Dev., 4, 591-610, https://doi.org/10.5194/ gmd-4-591-2011.

Miguez-Macho, G., G. L. Stenchikov, and A. Robock, 2004: Spectral nudging to eliminate the effects of domain position and geometry in regional climate model simulations. J. Geophys. Res., 109, D13104, https://doi.org/10.1029/2003JD004495.

Milton, S. F., G. Greed, M. E. Brooks, J. Haywood, B. Johnson, R. P. Allan, A. Slingo, and W. M. F. Grey, 2008: Modeled and observed atmospheric radiation balance during the West African dry season: Role of mineral dust, biomass burning aerosol, and surface albedo. J. Geophys. Res., 113, D00C02, https://doi.org/10.1029/2007JD009741.

MISR Science Team, 2015: Terra/MISR level 3, component global aerosol monthly NetCDF, version 4. NASA Atmospheric Science Data Center, accessed 2 March 2018, https://doi.org/10.5067/Terra/MISR/MIL3MAEN_L3.004.

Myhre, G., C. R. Hoyle, T. F. Berglen, B. T. Johnson, and J. M. Haywood, 2008: Modeling of the solar radiative impact of biomass burning aerosols during the Dust and Biomassburning Experiment (DABEX). J. Geophys. Res., 113, D00C16, https://doi.org/10.1029/2008JD009857.

Nakanishi, M., and H. Niino, 2006: An improved Mellor-Yamada level 3 model: Its numerical stability and application to a regional prediction of advection fog. Bound.-Layer Meteor., 119, 397-407, https://doi.org/10.1007/s10546-005-9030-8.

— , and - 2009: Development of an improved turbulence closure model for the atmospheric boundary layer. J. Meteor. Soc. Japan, 87, 895-912, https://doi.org/10.2151/jmsj.87.895.

NOAA/NCEP, 2000: NCEP FNL Operational Model Global Tropospheric Analyses, continuing from July 1999 (updated daily). National Center for Atmospheric Research Computational and Information Systems Laboratory Research Data Archive, accessed 29 June 2017, https://doi.org/10.5065/ D6M043C6. 
Nishihama, M., R. Wolfe, D. Solomon, F. Patt, J. Blanchette, A. Fleig, and E. Masuoka, 1997: MODIS level 1A Earth location: Algorithm theoretical basis document, version 3.0. MODIS Science Data Support Team Rep., SDST-092, 147 pp.

Omar, A. H., and Coauthors, 2009: The CALIPSO automated aerosol classification and lidar ratio selection algorithm. J. Atmos. Oceanic Technol., 26, 1994-2014, https://doi.org/ 10.1175/2009JTECHA1231.1.

Peters-Lidard, C. D., and Coauthors, 2015: Integrated modeling of aerosol, cloud, precipitation and land processes at satelliteresolved scales. Environ. Modell. Software, 67, 149-159, https://doi.org/10.1016/j.envsoft.2015.01.007.

Peterson, D., J. Wang, C. Ichoku, E. Hyer, and V. Ambrosia, 2013: A sub-pixel-based calculation of fire radiative power from MODIS observations: 1: Algorithm development and validation. Remote Sens. Environ., 129, 262-279, https:// doi.org/10.1016/j.rse.2012.10.036.

— E. E. Hyer, and J. Wang, 2014: Quantifying the potential for high-altitude smoke injection in the North American boreal forest using the standard MODIS fire products and subpixelbased methods. J. Geophys. Res. Atmos., 119, 3401-3419, https://doi.org/10.1002/2013JD021067.

Polivka, T. N., J. Wang, L. T. Ellison, E. J. Hyer, and C. Ichoku, 2016: Improving nocturnal fire detection with the VIIRS daynight band. IEEE Trans. Geosci. Remote Sens., 54, 5503-5519, https://doi.org/10.1109/TGRS.2016.2566665.

Reeves, C. E., and Coauthors, 2010: Chemical and aerosol characterisation of the troposphere over West Africa during the monsoon period as part of AMMA. Atmos. Chem. Phys., 10, 7575-7601, https://doi.org/10.5194/acp-10-7575-2010.

Roberts, G., M. J. Wooster, and E. Lagoudakis, 2009: Annual and diurnal African biomass burning temporal dynamics. Biogeosciences, 6, 849-866, https://doi.org/10.5194/bg-6-849-2009.

—_, and Coauthors, 2015: LSA SAF Meteosat FRP products-Part 2: Evaluation and demonstration of use in the Copernicus Atmosphere Monitoring Service (CAMS). Atmos. Chem. Phys., 15, 13 241-13267, https://doi.org/ 10.5194/acp-15-13241-2015.

Sakaeda, N., R. Wood, and P. J. Rasch, 2011: Direct and semidirect aerosol effects of southern African biomass burning aerosol. J. Geophys. Res., 116, D12205, https://doi.org/10.1029/2010JD015540.

Sayer, A. M., L. A. Munchak, N. C. Hsu, R. C. Levy, C. Bettenhausen, and M.-J. Jeong, 2014: MODIS collection 6 aerosol products: Comparison between Aqua's e-Deep Blue, Dark Target, and "merged" data sets, and usage recommendations. J. Geophys. Res. Atmos., 119, 13 965-13 989, https://doi.org/10.1002/ 2014JD022453.

Shi, J. J., and Coauthors, 2014: Implementation of an aerosolcloud-microphysics-radiation coupling into the NASA unified WRF: Simulation results for the 6-7 August 2006 AMMA special observing period. Quart. J. Roy. Meteor. Soc., 140, 2158-2175, https://doi.org/10.1002/qj.2286.

Skamarock, W. C., and Coauthors, 2008: A description of the Advanced Research WRF version 3. NCAR Tech. Note NCAR/TN-475+STR, 113 pp., https://dx.doi.org/10.5065/ D68S4MVH.

Solomos, S., and Coauthors, 2015: Smoke dispersion modeling over complex terrain using high resolution meteorological data and satellite observations-The FireHub platform. Atmos. Environ., 119, 348-361, https://doi.org/10.1016/j.atmosenv.2015.08.066.

Swap, R. J., and Coauthors, 2002: The Southern African Regional Science Initiative (SAFARI 2000): Overview of the dry season field campaign. S. Afr. J. Sci., 98, 125-130.
Tao, Z., H. Yu, and M. Chin, 2015: The role of aerosol-cloudradiation interactions in regional air quality-A NU-WRF study over the United States. Atmosphere, 6, 1045-1068, https://doi.org/10.3390/atmos6081045.

,$- \ldots$, and — 2016: Impact of transpacific aerosol on air quality over the United States: A perspective from aerosol-cloud-radiation interactions. Atmos. Environ., 125, 48-60, https://doi.org/10.1016/ j.atmosenv.2015.10.083.

Tewari, M., and Coauthors, 2004: Implementation and verification of the unified Noah land surface model in the WRF model. 20th Conf. on Weather Analysis and Forecasting/16th Conf. on Numerical Weather Prediction, Seattle, WA, Amer. Meteor. Soc., 14.2A, https://ams.confex.com/ams/pdfpapers/69061.pdf.

Trentmann, J., and Coauthors, 2006: Modeling of biomass smoke injection into the lower stratosphere by a large forest fire (Part I): Reference simulation. Atmos. Chem. Phys., 6, 5247-5260, https://doi.org/10.5194/acp-6-5247-2006.

Tummon, F., F. Solmon, C. Liousse, and M. Tadross, 2010: Simulation of the direct and semidirect aerosol effects on the southern Africa regional climate during the biomass burning season. J. Geophys. Res., 115, D19206, https://doi.org/10.1029/ 2009JD013738.

Van der Werf, G. R., and Coauthors, 2010: Global fire emissions and the contribution of deforestation, savanna, forest, agricultural, and peat fires (1997-2009). Atmos. Chem. Phys., 10, 11 707-11 735, https://doi.org/10.5194/acp-10-11707-2010.

Wang, J., S. A. Christopher, U. S. Nair, J. S. Reid, E. M. Prins, J. Szykman, and J. L. Hand, 2006: Mesoscale modeling of Central American smoke transport to the United States: 1. "Top-down" assessment of emission strength and diurnal variation impacts. J. Geophys. Res., 111, D05S17, https:// doi.org/10.1029/2005JD006416.

- Y. Yue, Y. Wang, C. Ichoku, L. Ellison, and J. Zeng, 2018: Mitigating satellite-based fire sampling limitations in deriving biomass burning emission rates: Application to WRF-Chem model over the northern sub-Saharan African region. J. Geophys. Res. Atmos., 123, 507-528, https://doi.org/10.1002/ 2017JD026840.

Winker, D. M., M. A. Vaughan, A. Omar, Y. Hu, K. A. Powell, Z. Liu, W. H. Hunt, and S. A. Young, 2009: Overview of the CALIPSO mission and CALIOP data processing algorithms. J. Atmos. Oceanic Technol., 26, 2310-2323, https://doi.org/ 10.1175/2009JTECHA1281.1.

Wooster, M. J., G. Roberts, G. L. W. Perry, and Y. J. Kaufman, 2005: Retrieval of biomass combustion rates and totals from fire radiative power observations: FRP derivation and calibration relationships between biomass consumption and fire radiative energy release. J. Geophys. Res., 110, D24311, https://doi.org/10.1029/2005JD006318.

—_, and Coauthors, 2015: LSA SAF Meteosat FRP products-Part 1: Algorithms, product contents, and analysis. Atmos. Chem. Phys., 15, 13 217-13 239, https://doi.org/ 10.5194/acp-15-13217-2015.

Yang, Z., J. Wang, C. Ichoku, E. Hyer, and J. Zeng, 2013: Mesoscale modeling and satellite observation of transport and mixing of smoke and dust particles over northern sub-Saharan African region. J. Geophys. Res. Atmos., 118, 12 139-12 157, https://doi.org/10.1002/2013JD020644.

Zhang, F., and Coauthors, 2014: Sensitivity of mesoscale modeling of smoke direct radiative effect to the emission inventory: A case study in northern sub-Saharan African region. Environ. Res. Lett., 9, 075002, https://doi.org/ 10.1088/1748-9326/9/7/075002. 